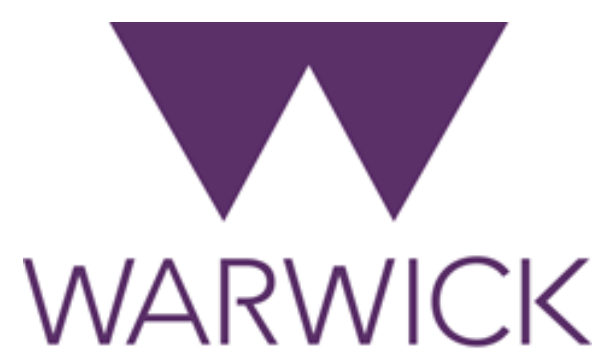

THE UNIVERSITY OF WARWICK

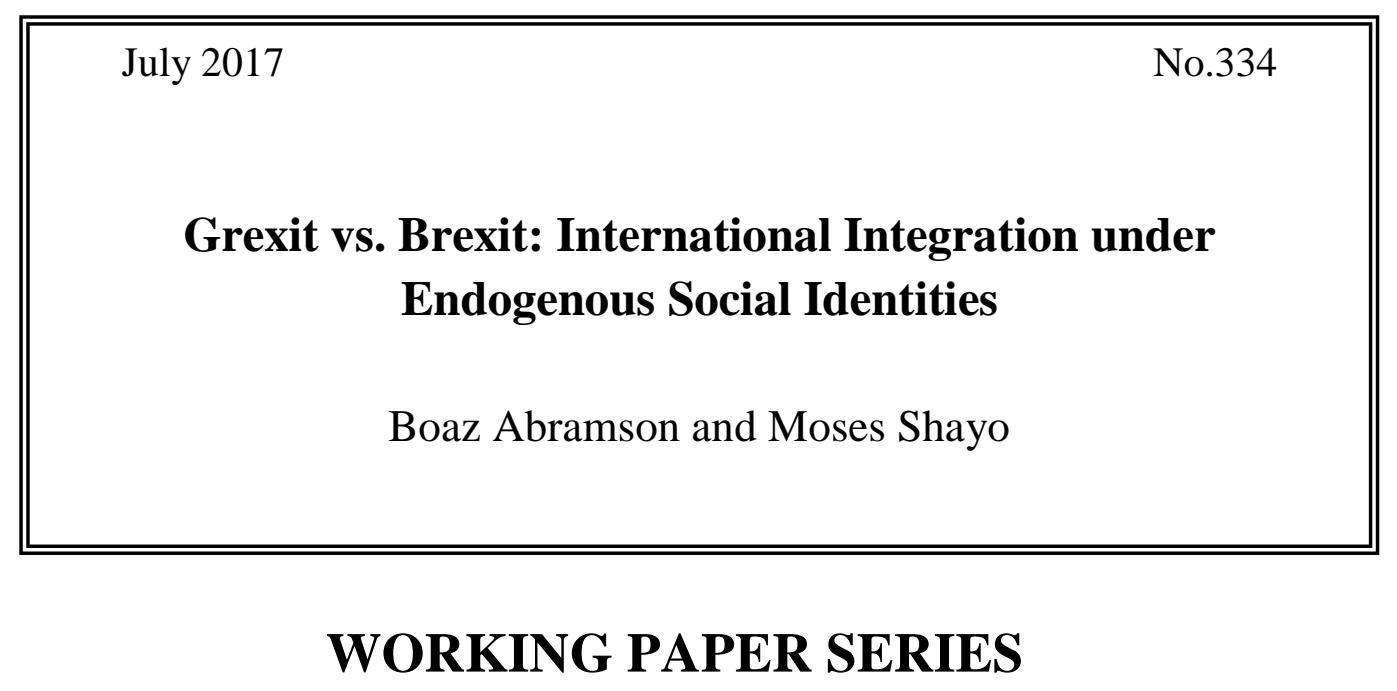

Centre for Competitive Advantage in the Global Economy

Department of Economics 


\title{
Grexit vs. Brexit: International Integration under Endogenous Social Identities*
}

\author{
Boaz Abramson \\ Department of Economics \\ Stanford University \\ boaza@stanford.edu
}

\author{
Moses Shayo \\ Department of Economics \\ The Hebrew University of Jerusalem \\ mshayo@huji.ac.il
}

July 2017

\begin{abstract}
International integration is not driven purely by economic considerations but may also be affected by identity politics. We propose a simple framework to study the effects of identity on integration, allowing identities themselves to be endogenous (a German citizen may identify as German but may also identify as European). We find that contrary to widespread intuitions, a robust union does not require that all members share a common identity. Furthermore, while national identification in the periphery leads to premature breakup, a common identity can sometimes lead to excessively large unions. Finally, a union is more fragile when periphery countries have high ex-ante status, whereas low-status countries are less likely to secede, even when between-country economic differences are large and union policies impose significant hardship. Brexit is more likely than Grexit.
\end{abstract}

${ }^{*}$ We thank Matthew Gentzkow, Joram Mayshar and participants at the First Bruneck Workshop on the Political Economy of Federalism (2016) and the Economic Research on Identity, Norms, and Narratives (ERINN) Inaugural Conference for valuable comments; Franz Buscha for sharing his data; and the European Union, ERC Starting Grant project no. 336659 for financial support. 


\section{Introduction}

Understanding the determinants and consequences of international integration has been a central concern for economists for a long time. The economic benefits of integration are fairly well understood and have been studied since the time of Adam Smith. ${ }^{1}$ The costs usually stem from having to satisfy divergent needs with a 'one size fits all' policy. For example, the literature on optimal currency unions starting with Mundell (1961) emphasizes that the loss of independent monetary policy hinders the ability to handle idiosyncratic shocks. A major lesson is that integration should take place when fundamental differences between the candidate countries are small and, more generally, when the benefits exceed the costs.

But integration is often shaped by additional forces. Consider European integration. From the beginning, it has been clear that economic considerations were not the main driving force (Schuman, 1950). Economists writing in the 1990s about the looming European Monetary Union recognized that the decision would not depend on the economic advantages and disadvantages. The prospects of developing a European identity that might transcend the bitter national identities of the past, as well as notions of national pride and status, appeared no less central than pure economic considerations. ${ }^{2}$

Recent European experience can appear equally puzzling from a standard economic perspective. Why did the UK vote to leave the EU despite a near unanimous view among economists that Brexit would have negative consequences for the British economy? And why did Greece join - and remain - in the Eurozone despite significant fundamental economic differences from the core, north-European countries, which require different monetary policy? As Den Haan et al. (2016) report, even most economists believe that the British decision to leave the EU was due to non-economic reasons. "Identity politics" has been widely discussed as a prominent cause underlying such decisions. However, we still lack a theoretical framework to help us think about the interplay between integration and social identity. This paper develops a simple model that takes the identity argument seriously and examines its implications.

We study economic and political unions when potential members of the union may care

\footnotetext{
${ }^{1}$ These benefits include gains from a larger market size in the presence of formal or informal barriers to international trade; economies of scale in the production of public goods; cross-regional insurance against imperfectly correlated shocks; and the internalization of cross-regional policy spillover effects. See Alesina, Spolaore and Wacziarg (2005) for a review of the costs and benefits of country size. Donaldson (2015) reviews recent work on the gains from market integration.

${ }^{2}$ See Feldstein (1997). Indeed, the composition of the Eurozone is hard to understand using the framework of optimal currency areas. Countries such as Sweden and Switzerland did not join, although they appeared like natural candidates based upon trade and co-movement in output and prices relative to the core Euro countries (Alesina, Barro and Tenreyro, 2002). On the other hand, countries more likely to require different monetary policy, like Greece and Portugal, did join.
} 
not just about their own country but also about the union as a whole. We refer to such altruistic motivations as social identities. Specifically, individual $i$ is said to identify with group $j$ if her utility is increasing in the material payoffs of members of group $j$. Importantly, identities are not necessarily fixed. A German citizen, for example, may identify as a German but may, to some extent, also identify as a European.

We embed this framework in a simple bargaining model between two countries: the Core and the Periphery. The Core sets a common policy for the union (e.g. monetary policy, debt policy, regulation, immigration policy). The Periphery then chooses whether to join the union and accept the common policy, or leave and set its own policy. As in standard models, unions in this model are less likely to be sustained in equilibrium the larger the differences in fundamental economic and political conditions between potential members. The question then becomes: what policies does the union adopt and at what point does the union disintegrate? We say that a union is more accommodating if its adopted policies better suit the needs of the politically weaker Periphery countries (at some cost to the politically dominant Core countries). We say that a union is more robust if it is sustained under larger fundamental differences between members.

For concreteness we use Europe as the running example. Thus, Germany may be thought of as a Core, politically dominant country within the union, while Greece and the UK are Periphery countries that consider whether to remain in the union. Members of each country may identify nationally (i.e. with their country) or they may identify with Europe as a whole. Accordingly, there are four possible identity profiles: $(C, P),(C, E),(E, P)$ and $(E, E)$, where the first entry in each pair denotes the identity of members of the Core and the second denotes the identity of members of the Periphery. For example, $(C, E)$ denotes the situation in which members of the Core identify nationally and Periphery members identify with Europe. ${ }^{3}$ Our focus in the first part of the analysis is on the subgame perfect Nash equilibria (SPNE) that emerge under a given profile of social identities.

A widely held view is that the European union would be more robust if only everyone in Europe identified more as European. Our analysis suggests a more nuanced view. First, consistent with common views as well as survey data (Bechtel, Hainmueller and Margalit, 2014), we find that a union is more accommodating when the citizens of the Core identify with Europe. This is because the Core takes into account the interests of the Periphery, and therefore opts for policy concessions even when it would not make any concessions if it was only interested in its own material payoffs. However, a union is less accommodating when

\footnotetext{
${ }^{3}$ We do not consider within-country heterogeneity in identification. One can think of these profiles as representing the identity of the majority in each country, in a majority-voting context. Shayo (2009) analyzes within-country variation in identification, showing that the poor are generally more likely than the rich to identify nationalistically, and that this tendency increases with the immigration of foreign workers.
} 
the Periphery identifies with Europe, essentially because in this case the Core can preserve the union with smaller concessions.

Remarkably, a union is most robust under the $(C, E)$ profile, i.e. when individuals from the Core identify with their country, while individuals from the Periphery identify with the union as a whole. In particular, this profile yields a more robust union than the profile $(E, E)$ in which everyone identifies with Europe. Essentially, when fundamental differences between the countries are very large, and the Periphery identifies with Europe, the union can still be sustained although at high material costs to the Periphery. When the Core identifies with Europe (but not when it identifies nationally), these costs of maintaining the union are partly internalized, leading to breakup.

Of course, preserving the union is not necessarily a goal in and of itself. When differences are large, the countries may be better off splitting. We show, however, that national identification in the Periphery implies that the union is less robust than is optimal from a material payoff perspective. This echoes the common reaction of economists to the costly decision of British voters on Brexit, which in turn was associated with strong national identification and weak identification with Europe (see data below). At the same time, a common identity does not always enhance overall material payoffs. There exist situations where it is materially optimal to dismantle the union, and yet it is sustained if the Periphery identifies with Europe. This complements Alesina and Spolaore (1997)'s result that under democracy nations tend to be too small. We obtain a similar result when individuals identify with their own nations, but not necessarily when they identify with larger units.

So far, we have taken social identities as given. However, a large social science literature argues that identities are not fixed - and respond to the social environment in systematic ways (see Chandra 2012; Shayo 2009). Indeed, the founders of the European Union were quite aware of this possibility, and believed that economic integration would promote European solidarity (Schuman 1950). Thus, while we can analyze the equilibrium policies under a specific profile of social identities, it is unclear whether this identity profile would in fact hold under the economic and political conditions that stem from these policies. We thus incorporate insights from social identity research to endogenize the decision whether to identify with one's country or with the union as a whole. In particular, an extensive literature in social psychology consistently finds that people tend to identify more with high-status groups than with low-status groups (see discussion of the literature below). But the status of both the union and of the potential member countries is itself endogenous to the economic policy, which in turn depends on the identity profile. We therefore propose an equilibrium concept - Social Identity Equilibrium (SIE) — in which both identities and policies are jointly determined. 
Consider first a baseline case, in which the countries are ex-ante symmetric in status. We show that in this case, in almost any equilibrium in which the union is sustained, the only possible social identity profile is $(C, E)$. Given any other identity profile, and fundamental differences sufficiently small such that the union can be sustained in SPNE, the chosen policies lead to a status advantage for the Core, which implies that non- $(C, E)$ profiles would not in fact be chosen by individuals.

For the case in which the Periphery has lower ex-ante status than the Core, we show that $(C, E)$ is the unique identity profile that can hold in SIE. However, when the Periphery has higher ex-ante status, the $(C, E)$ profile is less likely to be sustained and the union is less robust in SIE. Moreover, in any SIE in which the union disintegrates the social identity profile is $(E, P)$, i.e. the Core identifies with Europe but the Periphery identifies nationally.

Data. Figure 1 shows Eurobarometer data on national versus European identification in Greece and the UK. Specifically, it shows the proportion of the population that reports seeing itself as British (Greek) only rather than British (Greek) and European; European and British (Greek); or European only. Since the early 2000's, the British have tended to identify much more with their country than with Europe. Greeks, remarkably, have tended to identify more with Europe. This remained true even at the height of the debt crisis and continued to hold despite harsh austerity measures imposed on Greece and despite very high rates of disapproval with EU policy (reported in Stokes, 2016).

Data we collected in the UK prior to the Brexit vote (in May 2016) also indicated a very low level of European identification in the UK, compared to British identification. A month later (in late June 2016), we asked the same respondents whether and how they voted. As Figure 2 shows, British identification is strongly associated with voting to leave the EU. Of voters who saw themselves as "British only", $66 \%$ voted Leave, $28 \%$ voted Remain and the rest did not vote. In contrast, only $24.5 \%$ of voters who saw themselves as "British but also European" voted Leave ( $71 \%$ voted Remain).

Table 1 shows this relationship using a linear probability model (cols 1-5) and a probit (col 6). Consistent with Figure 2, the association in column 1 is highly significant both statistically and economically. Relative to those who see themselves as British only (the omitted category), individuals who see themselves as both British and European are more than 40 percentage points less likely to vote Leave. The difference appears even larger among those who place a higher priority on being European. In columns 2-5 we progressively add controls for demographics (age, gender and an indicator for being born in the UK), household income and education. Consistent with other studies, older, less-educated, and native voters were more likely to support Brexit (see Becker, Fetzer and Novy, 2017). Higher 


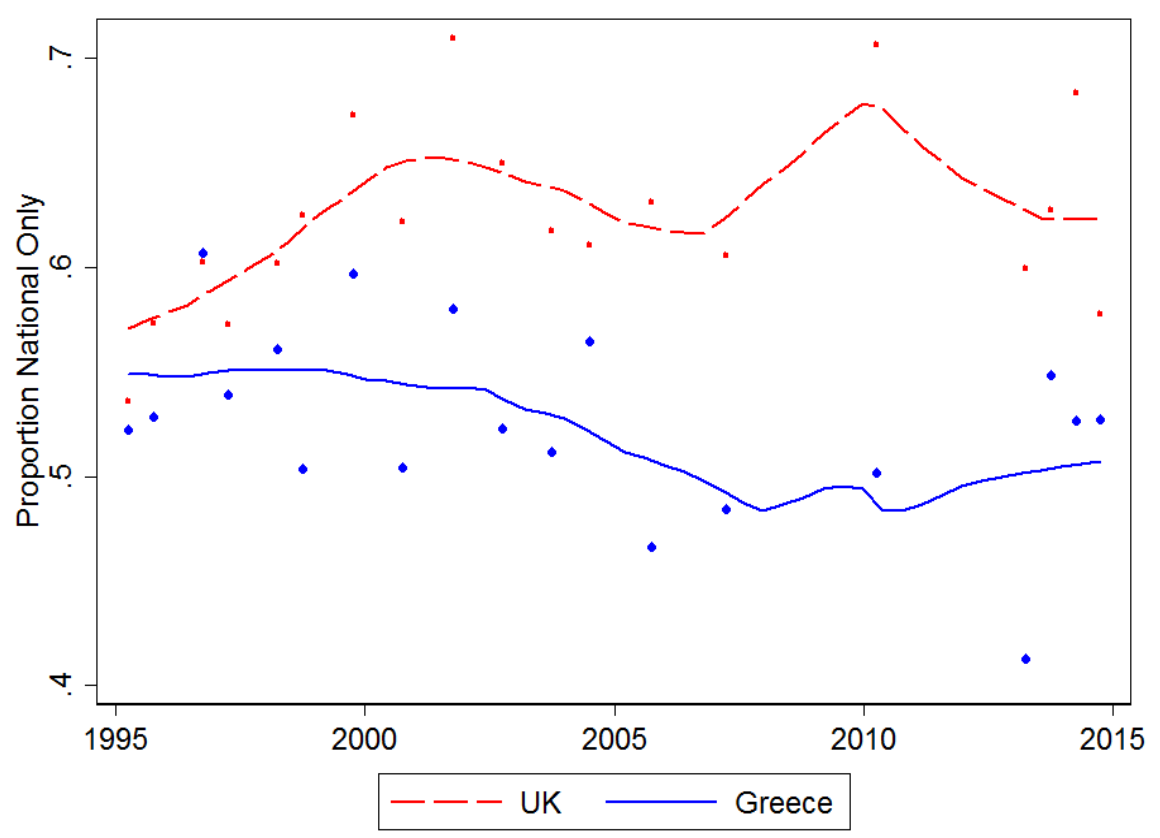

Figure 1: National vs. European identity in the UK and Greece

Note: Eurobarometer data. Each dot is a nationally representative sample. Lines are kernel-weighted local polynomial regressions. The figure shows the proportion choosing the first answer from the following question: Do you see yourself as...1.[Nationality] only; 2. [Nationality] and European; 3. European and [Nationality]; 4. European only. We thank Franz Buscha for sharing the data.

income individuals and females appear less likely to vote Leave, but these associations are imprecisely estimated and weaken once we control for education (cols 4-6). To account for geographical variation in voting patterns, column 5 further controls for the county of residence. Remarkably, the association between voting and British/European identification remains very strong in all specifications. It is perhaps also worth noticing that adding variables such as income, age and education does not greatly increase the explanatory power of the regression beyond what is explained by the identity variable alone, measured a month before the referendum.

To sum up, significant fundamental differences between Greece (a low ex-ante status country) and the core north-European countries have not prevented Greece from joining the Euro, and unaccommodating EU policies have not led to a Greek exit from the Eurozone. ${ }^{4}$

\footnotetext{
${ }^{4}$ While the potential costs of leaving the Euro were clear, prominent economists like Joseph Stiglitz have argued that for Greece "leaving the Euro will be painful, but staying in the Euro will be more painful" (Stiglitz, J., The Future of Europe, UBS International Center of Economics in Society, University of Zurich, Basel, January 27, 2014).
} 


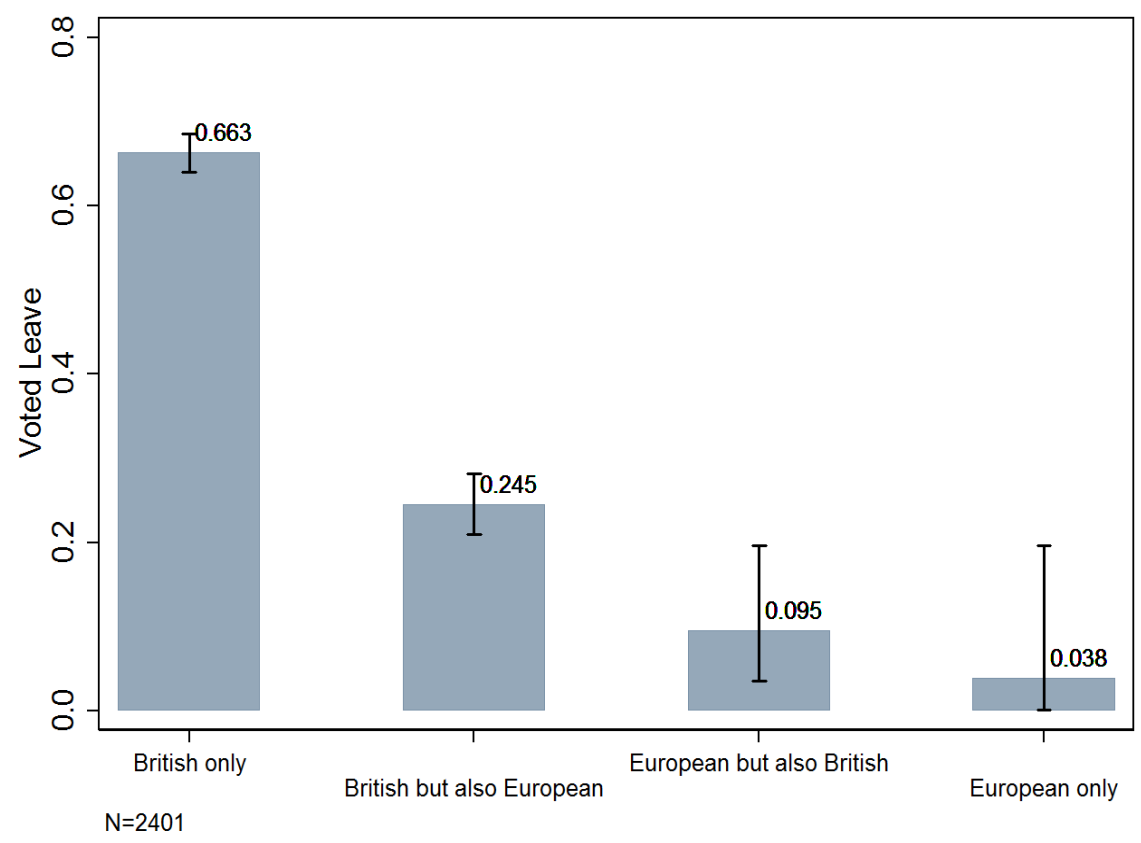

Figure 2: British Identification and Voting to Leave the EU

Note: Data collected by the authors from a representative sample of voters residing in England (i.e. excluding Scotland, Wales and Northern Ireland). A month prior to the referendum (in May 16-22, 2016), voters were asked the following question: Do you see yourself as...? British only; British but also European; European but also British; European only; Neither European nor British. For each of the first four respondent groups, the figure shows the proportion (and 95\% CI) who voted "Leave" in the referendum on June 23, 2016.

As suggested by Figure 1, this was accompanied by relatively high levels of identification with Europe. At the same time, Britain (high ex-ante status) not only stayed out of the Eurozone but voted to leave the European Union, despite the latter being relatively accommodating to British demands and with the overwhelming view among economists that leaving the EU would have negative consequences. ${ }^{5}$ Considering the relatively small economic differences between Britain and the core EU countries of Germany and France, it appears that these phenomena might be better understood as driven by an interaction of economic forces with social identities.

\footnotetext{
${ }^{5} \mathrm{~A}$ survey of members of the Royal Economic Society and the Society of Business Economists conducted in May 2016 indicated that $72 \%$ of economists thought that the most likely outcome of Britain leaving the EU would be a negative impact on UK real GDP (https://www.ipsosmori.com/researchpublications/researcharchive/3739/economists-Views-on-Brexit.aspx). Additional surveys conducted by Bloomberg (https://www.bloomberg.com/news/articles/2016-02-24/how-low-could-poundfall-in-a-brexit-economists-say-try-1985) and the Financial Times (https://www.ft.com/content/1a86ab36afbe-11e5-b955-1a1d298b6250) show a similar pattern.
} 
Table 1: Voting for Brexit and British/European Identity

\begin{tabular}{|c|c|c|c|c|c|c|}
\hline & \multicolumn{5}{|c|}{ OLS } & \multirow{2}{*}{$\begin{array}{c}\text { Probit } \\
(6) \\
\end{array}$} \\
\hline & (1) & (2) & (3) & (4) & (5) & \\
\hline \multicolumn{7}{|l|}{ Identity } \\
\hline British but also European & $\begin{array}{c}-0.419 * * * \\
(0.021)\end{array}$ & $\begin{array}{c}-0.412 * * * \\
(0.021)\end{array}$ & $\begin{array}{c}-0.406 * * * \\
(0.021)\end{array}$ & $\begin{array}{c}-0.372 * * * \\
(0.022)\end{array}$ & $\begin{array}{c}-0.365^{* * *} \\
(0.023)\end{array}$ & $\begin{array}{c}-0.394^{* * *} \\
(0.023)\end{array}$ \\
\hline European but also British & $\begin{array}{c}-0.568^{* * *} \\
(0.039)\end{array}$ & $\begin{array}{c}-0.518^{* * *} \\
(0.044)\end{array}$ & $\begin{array}{c}-0.515^{* * *} \\
(0.045)\end{array}$ & $\begin{array}{c}-0.481^{* * *} \\
(0.045)\end{array}$ & $\begin{array}{c}-0.463^{* * *} \\
(0.046)\end{array}$ & $\begin{array}{c}-0.526^{* * *} \\
(0.050)\end{array}$ \\
\hline European only & $\begin{array}{c}-0.625 * * * \\
(0.039)\end{array}$ & $\begin{array}{c}-0.535^{* * *} \\
(0.047)\end{array}$ & $\begin{array}{c}-0.527 * * * \\
(0.047)\end{array}$ & $\begin{array}{c}-0.491 * * * \\
(0.049)\end{array}$ & $\begin{array}{c}-0.474^{* * *} \\
(0.047)\end{array}$ & $\begin{array}{c}-0.587 * * * \\
(0.062)\end{array}$ \\
\hline Neither European nor British & $\begin{array}{c}-0.116^{* *} \\
(0.056)\end{array}$ & $\begin{array}{l}-0.094 * \\
(0.054)\end{array}$ & $\begin{array}{l}-0.105^{*} \\
(0.054)\end{array}$ & $\begin{array}{l}-0.085 \\
(0.054)\end{array}$ & $\begin{array}{l}-0.085 \\
(0.053)\end{array}$ & $\begin{array}{l}-0.080 \\
(0.057)\end{array}$ \\
\hline Age & & $\begin{array}{c}0.020 * * * \\
(0.004)\end{array}$ & $\begin{array}{c}0.021^{* * *} \\
(0.004)\end{array}$ & $\begin{array}{c}0.019 * * * \\
(0.004)\end{array}$ & $\begin{array}{c}0.019 * * * \\
(0.004)\end{array}$ & $\begin{array}{c}0.023 * * * \\
(0.005)\end{array}$ \\
\hline Age Square & & $\begin{array}{c}-0.000^{* * *} \\
(0.000)\end{array}$ & $\begin{array}{c}-0.000 * * * \\
(0.000)\end{array}$ & $\begin{array}{c}-0.000^{* * * *} \\
(0.000)\end{array}$ & $\begin{array}{c}-0.000^{* * *} \\
(0.000)\end{array}$ & $\begin{array}{c}-0.000^{* * *} \\
(0.000)\end{array}$ \\
\hline Female & & $\begin{array}{l}-0.025 \\
(0.018)\end{array}$ & $\begin{array}{l}-0.032 * \\
(0.018)\end{array}$ & $\begin{array}{l}-0.025 \\
(0.018)\end{array}$ & $\begin{array}{l}-0.032 * \\
(0.019)\end{array}$ & $\begin{array}{l}-0.031 \\
(0.022)\end{array}$ \\
\hline Born in UK & & $\begin{array}{l}0.089 * * \\
(0.038)\end{array}$ & $\begin{array}{l}0.090 * * \\
(0.038)\end{array}$ & $\begin{array}{l}0.084^{* *} \\
(0.037)\end{array}$ & $\begin{array}{l}0.075 * * \\
(0.038)\end{array}$ & $\begin{array}{l}0.121^{* *} \\
(0.050)\end{array}$ \\
\hline $\ln$ (HH Income) & & & $\begin{array}{c}-0.038 * * * \\
(0.013)\end{array}$ & $\begin{array}{l}-0.020 \\
(0.013)\end{array}$ & $\begin{array}{l}-0.021 \\
(0.013)\end{array}$ & $\begin{array}{l}-0.022 \\
(0.016)\end{array}$ \\
\hline \multicolumn{7}{|l|}{ Education } \\
\hline GSCE, GNQV or equivalent & & & & $\begin{array}{l}-0.010 \\
(0.044)\end{array}$ & $\begin{array}{l}-0.004 \\
(0.045)\end{array}$ & $\begin{array}{l}-0.013 \\
(0.054)\end{array}$ \\
\hline A-Levels or equivalent & & & & $\begin{array}{l}-0.028 \\
(0.046)\end{array}$ & $\begin{array}{l}-0.030 \\
(0.046)\end{array}$ & $\begin{array}{l}-0.029 \\
(0.055)\end{array}$ \\
\hline Professional qualifications & & & & $\begin{array}{c}0.026 \\
(0.048)\end{array}$ & $\begin{array}{c}0.030 \\
(0.048)\end{array}$ & $\begin{array}{c}0.032 \\
(0.058)\end{array}$ \\
\hline Academic degree & & & & $\begin{array}{c}-0.146^{* * *} \\
(0.046)\end{array}$ & $\begin{array}{c}-0.138 * * * \\
(0.047)\end{array}$ & $\begin{array}{c}-0.166 * * * \\
(0.055)\end{array}$ \\
\hline County FE & No & No & No & No & Yes & No \\
\hline Observations & 2,485 & 2,485 & 2,462 & 2,462 & 2,462 & 2,462 \\
\hline R-squared / Pseudo R-squared & 0.154 & 0.187 & 0.190 & 0.205 & 0.224 & 0.162 \\
\hline
\end{tabular}

Related literature. A prominent result in the literature on economic integration is that countries with substantial dissimilarities should maintain policy independence (e.g. De Grauwe, 2014). We build on the work in political economy - starting with Alesina and Spolaore (1997) and Bolton and Roland (1997) — on the breakup and unification of countries, which highlights the tradeoff between economic gains to unification and the costs of heterogeneity. We start with a simple model that features this tradeoff and examine both how the introduction of social identity can modify the political equilibrium and how the political equilibrium affects identification patterns.

Many of the explanations of public attitudes towards integration have focused on economic factors. While standard economic models help explain some of the variation in attitudes towards international trade, non-economic factors appear to play an important role 
(Mayda and Rodrik, 2005). A burgeoning literature in political science examines public support for European integration in general and for specific policies like Eurozone bailouts. Attention has increasingly turned from economic factors to identity concerns which appear no less important - and which often interact with economic factors in significant ways (Bechtel, Hainmueller and Margalit, 2014; Hooghe and Marks, 2004, 2009; Serricchio, Tsakatika and Quaglia, 2013; Van Klingeren, Boomgaarden and De Vreese, 2013). Indeed, the interaction between integration policies and identity is a prominent concern in many European countries. However, it is not clear what the equilibrium is. Does a common identity necessarily produce a more stable union? And what identity patterns should we expect to emerge?

Finally, the paper builds on the growing economic literature on identity and how group membership shapes behavior (Akerlof and Kranton, 2000, 2010; Bénabou and Tirole, 2011; Benjamin, Choi and Strickland, 2010; Bisin and Verdier, 2001; Carvalho, 2013; Chen and Li, 2009; Shayo and Zussman, 2011, 2017). We also relate to the literature showing that cultural affiliation is associated with economic exchange. As in our model, the influence appears to run in both directions. Thus, Guiso, Sapienza and Zingales (2009) show that trade and investment flows between countries are associated with bilateral trust, which in turn is related to cultural similarities, while Maystre et al. (2014) argue theoretically and provide evidence that bilateral trade reduces bilateral cultural distance. Note however that while culture is often conceptualized as a set of norms and beliefs that evolve very slowly (e.g., Guiso, Sapienza and Zingales, 2006; Spolaore and Wacziarg, 2013; Tabellini, 2008; Voigtländer and Voth, 2012), a large body of social science research has shown that identities are quite fluid and can adjust to changes in the social environment even in the short run (see review in Sambanis, Schulhofer-Wohl and Shayo 2012). Status, in particular, is a central group characteristic in both theory and empirical research in social psychology. The basic argument is that a low group status results in unfavorable comparisons between the in-group and relevant other groups. As a result, members of lower status groups show less social identification than members of groups with higher status. ${ }^{6}$ In what follows we examine whether these insights might help us better understand the political economy of integration.

\footnotetext{
${ }^{6}$ Ellemers, Kortekaas and Ouwerkerk (1999). Empirically, identification is measured using either observed allocation decisions between ingroup and outgroup members or self-reported feelings and attitudes toward the ingroup and the outgroup. A meta-analysis of 92 experimental studies (including 145 independent samples) with high-status/low-status manipulation confirms that high status group members favor their ingroup over the outgroup significantly more than do low status group members (Bettencourt et al., 2001). Similar results emerge from field studies. Double-major university students identify more with their higher-status department, and are more likely to identify with a given department the lower is the status of the other department they major in (Roccas, 2003). And winning sports teams have long been shown to generate more identification (e.g. Cialdini et al. 1976).
} 


\section{Model}

We begin with a simple sequential game between two players, the "Core" of an economic union, denoted $C$, and a Periphery country $P$ that considers joining or exiting the union. As in Alesina and Spolaore (1997), unification entails economic gains to both countries (e.g. from increased trade), but means they both need to share a common policy (e.g. same immigration or monetary policy). For concreteness, we use the European Union and the Eurozone as the running examples of a union. In this context, Germany would be a Core country. Greece during 2010-2016 is one example of a Periphery country considering exit from the Eurozone ("Grexit"), while the UK during the 2016 Brexit debate is an example of a Periphery country considering exit from the EU. Other countries have also held negotiations with the European institutions over membership either in the Eurozone (Denmark, Poland) or in the EU. In 2004 ten countries joined the EU, and in 2007 two more joined, with most entrants from Eastern Europe. Denote by $E$ the super-ordinate category which includes both the Core and the Periphery (i.e. Europe as a whole). Let $\lambda \in(0.5,1)$ be the proportion of the total population of $E$ who are members of the Core.

Individuals residing in the Core and the Periphery countries have preferences over a compound policy instrument, which we denote $r_{i}$ for $i \in\{C, P\}$. This may include macroeconomic policy instruments such as the interest rate set by the monetary authority, the exchange rate regime, or various fiscal tools. It could also represent other policies that are jointly set in case of unification, such as regulation and immigration policy. Let $r_{i}^{*}$ be country $i$ 's ideal policy, from a standard, material payoff perspective. That is, it is the policy the country's citizens would most prefer in the absence of any identity concerns regarding other countries. Thus, differences in $r_{i}^{*}$ capture fundamental differences in economic conditions and preferences across countries. Without loss of generality, we will assume throughout the paper that $r_{C}^{*} \geq r_{P}^{*}$. For example, Germany requires higher interest rates than Greece or higher immigration rates than the UK.

The Core moves first and sets the policy instrument at some level $r_{C}=\hat{r}$. The Periphery then either accepts or rejects this policy. If it accepts then $r_{P}=r_{C}=\hat{r}$. If it rejects then it is free to set its own policy. Unification entails a per-capita benefit to both countries (or equivalently, breakup entails a cost) of size $\triangle$. This can come from, e.g., gains from trade, economies of scale in the production of public goods, or other potential benefits of unification

such as reducing the risk of conflict. The material payoff of a representative agent in country $i$ has the following form:

$$
V_{i}\left(r_{i}, \text { breakup }\right)=-\left(r_{i}-r_{i}^{*}\right)^{2}-\Delta * \text { breakup }
$$

where breakup is an indicator variable taking the value 1 if the two countries do not form 
a union and zero otherwise. Abusing notation slightly, we use $i$ to denote both a country and the representative agent of that country. Notice that we assume policy is "sticky", that is, once the Core sets the policy, the policy remains in place even if the Periphery rejects it. This makes sense if union policies are complex and cannot be changed overnight (e.g., even if the $\mathrm{UK}$ leaves the EU, it may take time for the EU to revise all policies and regulations that were put in place to accommodate British interests). In Appendix B we provide an analysis of the case where the Core is fully flexible in setting its policy once the Periphery leaves the union. The conclusions are qualitatively similar (except for part $b$ of Proposition 4).

Intuitively enough, unification occurs when the cross-country differences in ideal policies are small and the benefits to unification are large (see next section). This captures the main factors highlighted in the literature on the formation and breakup of unions. Our main focus is on how the equilibrium changes when we take into account social identities, namely the possibility that individuals care not only about their own material payoffs, but also about the payoffs of members of the group they identify with. Individuals may identify with their own country, e.g. as German, Greek or British. But they may also identify as European. We then ask two questions:

1. How will policies be set, and will unification take place, under different configurations of social identities? (Section 3).

2. If identities are not exogenously given, what configurations of social identities and policies hold in equilibrium? (Section 5).

As in Akerlof and Kranton (2000), we define social identification in terms of preferences. More concretely, think of an individual that belongs to several social groups, denoted by $j$. We say that individual $i$ identifies with group $j$ if she cares about the payoffs of the individuals in group $j$. Another way to think about it is that $i$ 's preferences are to some degree aligned with group $j$ 's preferences. Formally, let $S_{j}$ be the status of group $j$.

Definition 1. Individual $i$ is said to identify with group $j$ if her utility over outcomes is given by:

$$
U_{i j}\left(r_{C}, r_{P}, \text { breakup }\right)=V_{i}+\gamma S_{j}
$$

where $\gamma>0$.

The status of a group is affected by the material payoffs of its members, but we also allow for other, exogenous factors which can impact a group's status (history, culture, etc.). Such factors will play a role once identity is endogenously determined. Thus, the status of the two countries is: 


$$
S_{j}=\sigma_{j}+V_{j}\left(r_{j}\right), \text { for } j \in\{C, P\}
$$

where $\sigma_{j}$ captures all exogenous factors that affect the status of country $j$. Similarly, the status of Europe is given by :

$$
S_{E}=\sigma_{E}+\lambda V_{C}+(1-\lambda) V_{P}
$$

where $\sigma_{E}$ captures exogenous shocks to European status. We shall sometimes refer to $\sigma_{j}$ as the ex-ante status of group $j$ and to $S_{j}$ as its ex-post status.

Note that for an individual who identifies with her country, utility simplifies to $U_{i i}=$ $(1+\gamma) V_{i}+\gamma \sigma_{i}$. However, identifying with Europe implies a degree of altruism towards members of the other country.

We define two important properties of unions.

Definition 2. A union is (strictly) more robust if it is sustained under (strictly) larger fundamental differences $r_{C}^{*}-r_{P}^{*}$.

Finally, we say that a union is more accommodating if its policies are closer to the needs of the Periphery country. Formally:

Definition 3. A union is (strictly) more accommodating if the policy implemented is (strictly) closer to $r_{P}^{*}$, for any level of fundamental differences such that the union is sustained.

\section{$3 \quad$ Integration under Fixed Social Identities}

It is useful to begin with a general characterization of the Subgame Perfect Nash Equilibrium (SPNE) outcome under any given profile of identities. Throughout we impose that in case of indifference unification occurs. Denote by $\left(I D_{c}, I D_{P}\right)$ the social identity profile in which Core members identify with group $I D_{c} \in\{C, E\}$ and Periphery members identify with group $I D_{P} \in\{P, E\}$.

Proposition 1. Subgame Perfect Nash Equilibrium (SPNE). For any profile of social identities $\left(I D_{c}, I D_{p}\right)$, there exist cutoffs $R_{1}=R_{1}\left(I D_{c}, I D_{p}\right)$ and $R_{2}=R_{2}\left(I D_{c}, I D_{p}\right)$ and policies (functions of $r_{C}^{*}$ and $r_{P}^{*}$ ) $\widehat{r}_{C}=\widehat{r}_{C}\left(I D_{c}, I D_{p}\right)$ and $\widehat{r}_{P}=\widehat{r}_{P}\left(I D_{c}, I D_{p}\right)$, such that $R_{1} \leq R_{2}, \widehat{r}_{P}<\widehat{r}_{C}$ and:

a. if $r_{C}^{*}-r_{P}^{*} \leq R_{1}$ then in SPNE unification occurs and $r_{C}=r_{P}=\widehat{r}_{C}$;

b. if $R_{1}<r_{C}^{*}-r_{P}^{*} \leq R_{2}$ then in SPNE unification occurs and $r_{C}=r_{P}=\widehat{r}_{P}$;

c. if $r_{C}^{*}-r_{P}^{*}>R_{2}$ then in SPNE breakup occurs and $r_{C}=r_{C}^{*}, r_{P}=r_{P}^{*}$.

All proofs are in the Appendix. 


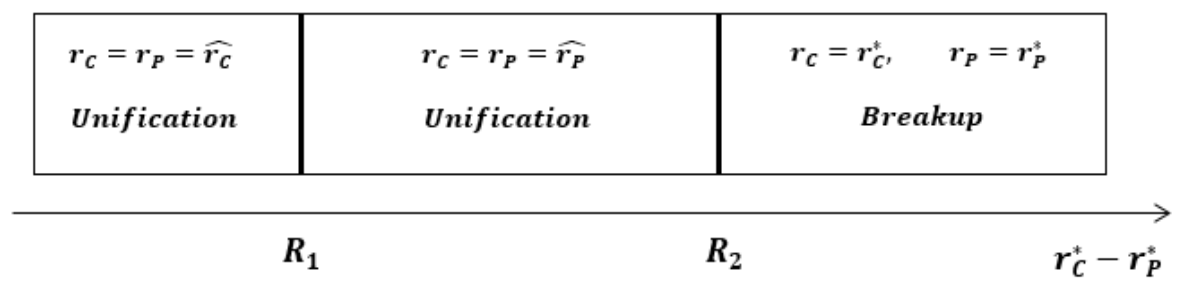

Figure 3: General Characterization of SPNE

Figure 3 illustrates. $\widehat{r}_{C}$ reflects the Core's chosen policy when there is no threat of secession. This may or may not be equal to $r_{C}^{*}$, depending on the Core's identity. Now, when fundamental differences between the countries $\left(r_{C}^{*}-r_{P}^{*}\right)$ are small relative to the cost of dismantling the union, the Periphery country would rather accept $\widehat{r}_{C}$ than set its own ideal policy and suffer the cost of breakup. As a result, the Core sets the policy to $\widehat{r}_{C}$. For larger fundamental differences between the countries (or lower costs of breakup), i.e. when $r_{C}^{*}-r_{P}^{*}>R_{1}$, the Core cannot set the policy to $\widehat{r}_{C}$ while keeping the Periphery as part of the union. However, as long as these differences are smaller than $R_{2}$, the Core can set its policy at a lower level $\hat{r}_{P}$ which would keep the Periphery in the union and still be preferable to breakup. In equilibrium the Periphery country is exactly indifferent between staying in the union and exiting. Finally, when $r_{C}^{*}-r_{P}^{*}$ is sufficiently large relative to $\Delta$, i.e. when $r_{C}^{*}-r_{P}^{*}>R_{2}$, the cost required to keep the Periphery in the union exceeds the benefits to the Core. In this case breakup occurs and policies are set to $r_{C}^{*}$ and $r_{P}^{*}$.

\subsection{Results}

We start by stating the two main results, and then examine the SPNE under each of the possible identity profiles.

\section{Proposition 2. Robustness}

a. The union is more robust when the Core identifies with the nation than when it identifies with Europe: $R_{2}\left(C, I D_{P}\right) \geq R_{2}\left(E, I D_{P}\right)$ for all $I D_{P} \in\{P, E\}$.

b. The union is strictly more robust when the Periphery identifies with Europe than when it identifies with the nation: $R_{2}\left(I D_{C}, E\right)>R_{2}\left(I D_{C}, P\right)$ for all I $D_{C} \in\{C, E\}$. 


\section{Proposition 3. Accommodation}

a. For any given Periphery identity, the union is more accommodating if Core members identify with Europe rather than with their nation.

b. For any given Core identity, the union is more accommodating if members of the Periphery identify with their nation rather than with Europe.

These results naturally lead to the following corollary:

Corollary 1. The union is the most robust and least accommodating under the $(C, E)$ profile.

To understand the mechanisms underlying these results and the way different identities play out, we now discuss in some detail each of the four possible social identity profiles.

Case $1(C, P)$ : Both Core and Periphery identify with their own country. This case serves as a convenient benchmark. It essentially replicates the standard economic analysis of economic integration, in which each country is only interested in its own material payoffs. Utilities in this case are:

$$
\begin{aligned}
& U_{C C}=\gamma \sigma_{C}-(1+\gamma)\left(\left(r_{C}-r_{C}^{*}\right)^{2}+\Delta * \text { breakup }\right) \\
& U_{P P}=\gamma \sigma_{P}-(1+\gamma)\left(\left(r_{P}-r_{P}^{*}\right)^{2}+\Delta * \text { breakup }\right)
\end{aligned}
$$

The cutoffs for unification and the policies in this case are specified in Lemma 1.

\section{Lemma 1.}
a. $R_{1}(C, P)=\sqrt{\triangle}, \quad R_{2}(C, P)=2 \sqrt{\triangle}$,
b. $\widehat{r}_{C}(C, P)=r_{C}^{*}, \quad \widehat{r}_{P}(C, P)=r_{P}^{*}+\sqrt{\triangle}$.

To get a sense of the basic features of this case, the left panel in Figure 4 plots the equilibrium utilities of the agents in the two countries as a function of the fundamental differences $r_{C}^{*}-r_{P}^{*}$ between them (for a given $\Delta$ ). Utility in both Core (top graph) and Periphery (bottom) is non-increasing in the economic differences: both Core and Periphery individuals are better off when fundamental differences between the countries are low and no major concessions are needed for the union to be sustained. For the Periphery, utility starts to decline as soon as their ideal policy differs from the Core's. However, since the Core cares only about its own material payoff, it continues to gain the maximum utility as long as it is able to impose $\widehat{r}_{C}(C, P)=r_{C}^{*}$ on the union. Core utility starts to decline only when it starts making concessions, setting its policy to $\widehat{r}_{P}(C, P)$. At this point the Periphery is kept at its reservation utility: the utility it gains under breakup. Finally, once fundamental differences 

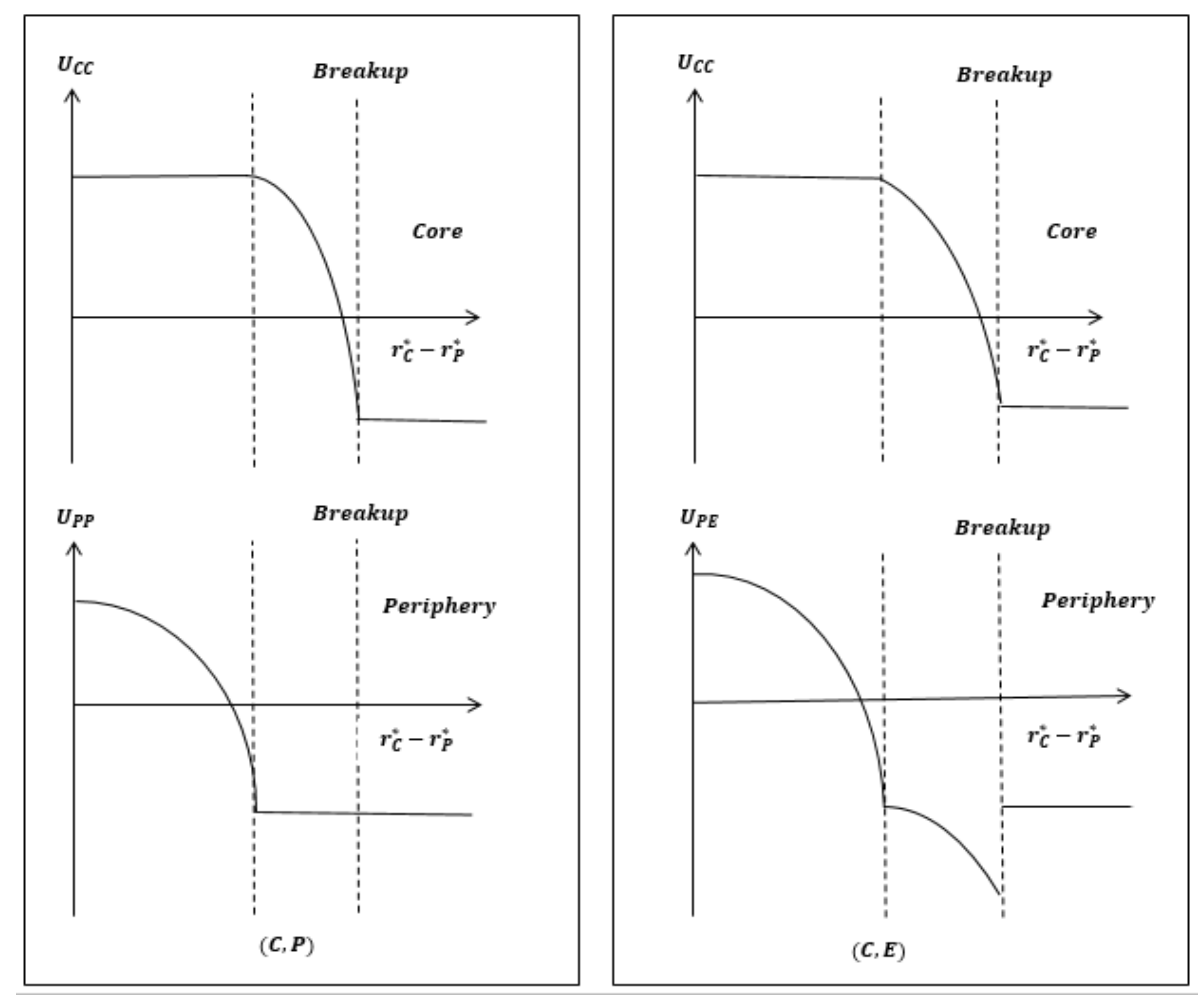

Figure 4: Utilities when the Core Identifies with Own Country: Cases 1-2

are large enough, breakup occurs and policies are set to their ideal levels. Utilities therefore no longer depend on $r_{C}^{*}-r_{P}^{*}$.

Case $2(C, E)$ : Core Identifies with own Country and Periphery identifies with Europe

In this case utility in the Core is unchanged from equation (5). Using equations (2) and (4), Periphery utility is:

$$
U_{P E}=\gamma \sigma_{E}-(1+\gamma-\gamma \lambda)\left(r_{P}-r_{P}^{*}\right)^{2}-\gamma \lambda\left(r_{C}-r_{C}^{*}\right)^{2}-(1+\gamma) \triangle * \text { breakup. }
$$

The following lemma provides the cutoffs and policies.

\section{Lemma 2.}
a. $R_{1}(C, E)=\sqrt{\frac{(1+\gamma) \triangle}{1+\gamma-\gamma \lambda}}, \quad R_{2}(C, E)=\sqrt{\triangle}+\sqrt{\frac{(1+\gamma) \triangle}{1+\gamma-\gamma \lambda}}$,
b. $\widehat{r}_{C}(C, E)=r_{C}^{*}, \quad \widehat{r}_{P}(C, E)=r_{P}^{*}+\sqrt{\frac{(1+\gamma) \triangle}{1+\gamma-\gamma \lambda}}$.

Comparing Lemmas 2 and 1 provides some important insights into the workings of social identity. The lemmas are also illustrated in Figure 6. First, note that $R_{1}(C, E)>R_{1}(C, P)$. 
Because the Periphery is now concerned not only with its own material payoff but also with Europe as a whole, it accepts $r_{C}^{*}$ at relatively high levels of fundamental differences. Indeed, $R_{1}(C, E)$ is increasing in $\lambda$ which captures the importance of the Core in European material payoffs.

Second, $\widehat{r}_{P}(C, E)>\widehat{r}_{P}(C, P)$. Thus, even when the Core makes concessions in order to sustain the union, these concessions are smaller than what was needed when the Core identified nationally. Again, since the Periphery cares about Europe as whole, it internalizes the wider policy implications for Europe of a more accommodating policy. Hence, the larger the concessions the Core makes, the larger the cost of dismantling the union from the point of view of the Periphery. This means that by making concessions the Core reduces the Periphery's reservation utility, which in effect allows the Core to preserve the union with smaller concessions. This can be seen in the bottom right panel of Figure 4: in the intermediate range, as fundamental differences increase, the very act of making concessions drives down the Periphery's utility and allows for smaller concessions.

Finally, these considerations allow the union to be sustained under larger fundamental differences than would be possible when each country only cares about itself. In other words, $R_{2}(C, E)>R_{2}(C, P)$. Note that the difference between $R_{2}(C, E)$ and $R_{2}(C, P)$ - i.e the range of fundamental differences over which the union is sustained under $(C, E)$ but not under $(C, P)$-depends positively on three factors: the cost of breakup $\triangle$, the size of the Core $\lambda$, and the weight the Periphery places on European status $\gamma$. An increase in any one of these tends to make breakup more costly for the Periphery when it identifies with Europe, which reinforces the above dynamic.

It is interesting to note that once fundamental differences are so large that the union cannot be sustained even though the Periphery identifies as European, the Core does not make any concessions, and hence the Periphery does not suffer any utility loss stemming from losses to Europe brought about by policy concessions. This yields a discontinuous jump in Periphery utility at breakup.

\section{Case $3(E, P)$ : Core identifies with Europe and Periphery identifies with own Country}

Periphery utility in this case is given by equation (6). Using equations (2) and (4) the Core utility is given by

$$
U_{C E}=\gamma \sigma_{E}-(1+\gamma \lambda)\left(r_{C}-r_{C}^{*}\right)^{2}-\gamma(1-\lambda)\left(r_{P}-r_{P}^{*}\right)^{2}-(1+\gamma) \triangle * \text { breakup }
$$

and the results of this game are summarized in Lemma 3. 

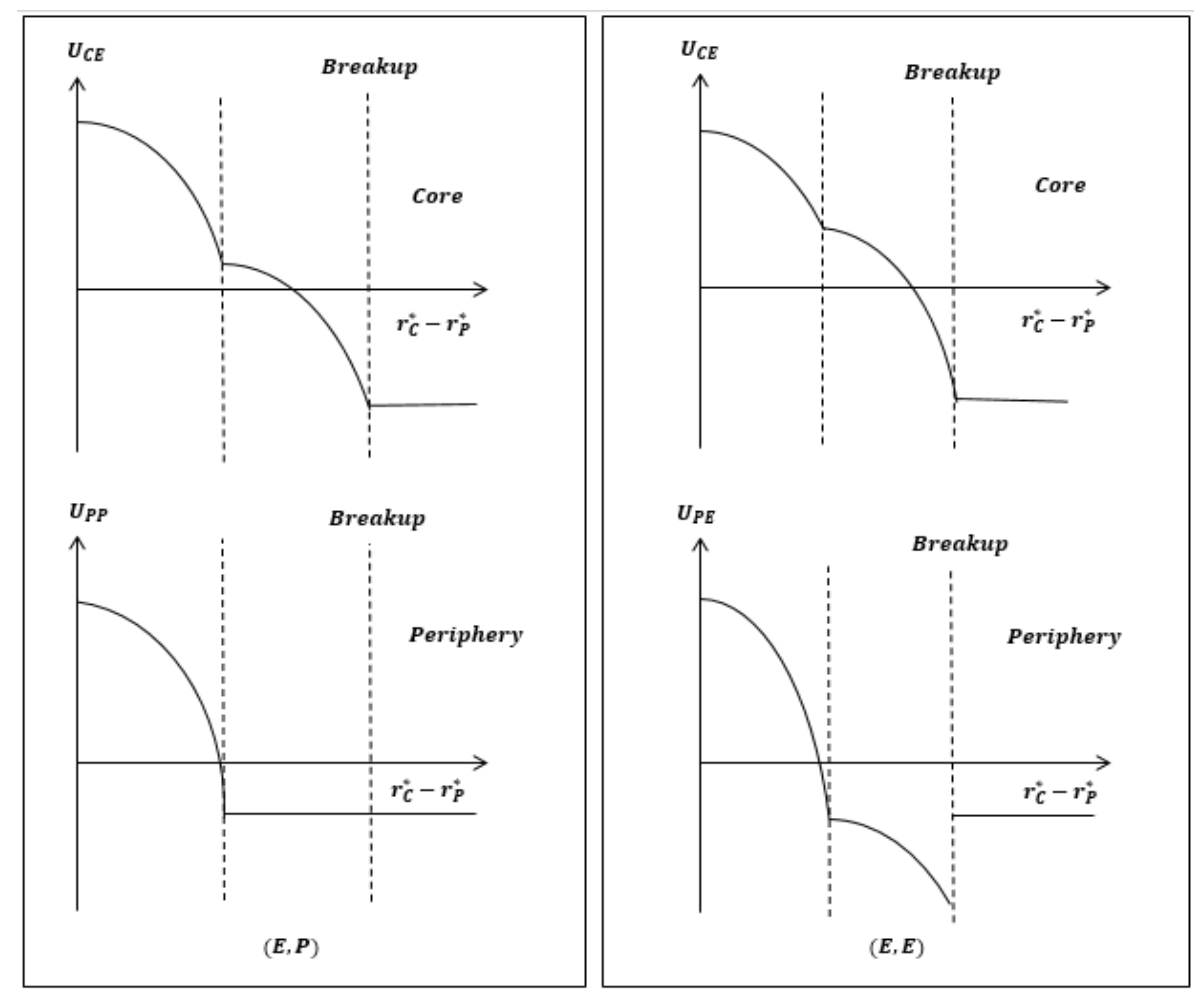

Figure 5: Utilities when the Core Identifies with Europe: Cases 3-4

Note: The figure is drawn for the case where $R_{1}(E, E)<R_{2}(E, E)$.

\section{Lemma 3.}
a. $R_{1}(E, P)=\frac{1+\gamma}{1+\gamma \lambda} \sqrt{\triangle}, \quad R_{2}(E, P)=2 \sqrt{\triangle}$,
b. $\widehat{r}_{C}(E, P)=\frac{(1+\gamma \lambda) r_{C}^{*}+\gamma(1-\lambda) r_{P}^{*}}{1+\gamma}, \quad \widehat{r}_{P}(E, P)=r_{P}^{*}+\sqrt{\triangle}$.

Again, it is instructive to compare this case to the benchmark Case $1(C, P)$. First, $\widehat{r}_{C}(E, P)<\widehat{r}_{C}(C, P)$. That is, at low levels of fundamental differences, the union is more accommodating since the Core now internalizes, to some extent, the policy effects on Europe as a whole. Thus, policy is set as some weighted average between the ideal policies of the two countries, with the weights reflecting their relative size and the extent of the Core's altruism towards Europe. As seen in Figure 5, top left panel, larger differences in policy needs between the Core and the Periphery are now reflected in utility losses to the Core.

This, however, does not imply that the union is more robust. At some point, this policy which takes into account wider European considerations - $\widehat{r}_{C}(E, P)$ - is not sufficient to keep the Periphery in the union. ${ }^{7}$ Further concessions need to be made. However, since the

\footnotetext{
${ }^{7}$ The reason is that the Core identifies with Europe as a whole and not exclusively with the Periphery. Since European status depends more on the Core's than on the Periphery's material payoffs, the chosen policy is not the ideal policy from the Periphery's perspective, even if the Core places a very high weight on European status.
} 
Periphery cares only about its own payoffs, the policy required to keep it in the union is exactly the same as in Case 1 . Hence $\widehat{r}_{P}(E, P)=\widehat{r}_{P}(C, P)$.

Furthermore, breakup occurs at the same level of fundamental differences as in Case 1: $R_{2}(E, P)=R_{2}(C, P)$. The reason is that once fundamental differences are above $R_{1}(E, P)$, the Periphery's utility is held constant at the utility obtained under breakup (Figure 5, bottom left panel). Hence the only factor shifting European material payoffs is Core material payoffs. Once fundamental differences are such that these payoffs are higher under breakup than under unification, breakup takes place. The upshot is that, perhaps surprisingly, the fact that the Core identifies with Europe does not prohibit or even delay breakup.

\section{Case $4(E, E)$ : Both Core and Periphery identify with Europe}

Finally, we turn to the case that, on the face of it, would seem like the most favorable for European integration: when everyone identifies with Europe.

\section{Lemma 4.}

$$
\begin{aligned}
& \text { a. } R_{1}(E, E)= \begin{cases}\frac{1+\gamma}{1+\gamma \lambda} \sqrt{\frac{(1+\gamma) \triangle}{(1+\gamma-\gamma \lambda)}} & \text { if } \gamma(1-\lambda) \leq \sqrt{1+\gamma \lambda} \\
\sqrt{\frac{(1+\gamma)^{2} \triangle}{\gamma(1-\lambda)(1+\gamma \lambda)}} & \text { if } \gamma(1-\lambda)>\sqrt{1+\gamma \lambda}\end{cases} \\
& R_{2}(E, E)= \begin{cases}\sqrt{\frac{(1+\gamma) \triangle}{(1+\gamma-\gamma \lambda)}}+\sqrt{\frac{(1+\gamma) \triangle}{(1+\gamma-\gamma \lambda)(1+\gamma \lambda)}} & \text { if } \gamma(1-\lambda) \leq \sqrt{1+\gamma \lambda} \\
\sqrt{\frac{(1+\gamma)^{2} \triangle}{\gamma(1-\lambda)(1+\gamma \lambda)}}, & \text { if } \gamma(1-\lambda)>\sqrt{1+\gamma \lambda}\end{cases} \\
& \text { b. } \widehat{r}_{C}(E, E)=\frac{(1+\gamma \lambda) r_{C}^{*}+\gamma(1-\lambda) r_{P}^{*}}{1+\gamma}, \quad \widehat{r}_{P}(E, E)=r_{P}^{*}+\sqrt{\frac{(1+\gamma) \triangle}{(1+\gamma-\gamma \lambda)}} \text {. }
\end{aligned}
$$

Note first that in this case, $R_{1}$ may coincide with $R_{2}$. This happens in particular when $\gamma$ is sufficiently large. Intuitively, if $\gamma$ is very large, both Core and Periphery have similar preferences (as they both mainly care about European payoffs). Once the Periphery prefers breakup to unification under $\widehat{r}_{C}(E, E)$ (the policy that maximizes these same preferences under unification), then so does the Core. Hence there is no region where the Core makes concessions to keep the Periphery in the union.

More generally, we see that, as in Case 3, at low levels of fundamental differences, policy is accommodating. The Core-being concerned with both own and European payoffs - sets the policy at some weighted average of $r_{C}^{*}$ and $r_{P}^{*}$. And as in Case 2, the fact that the Periphery identifies with Europe allows the Core to set its most preferred policy over a wider range than would be possible if the Periphery only cared about itself $\left(R_{1}(E, E)>R_{1}(E, P)\right)$. 


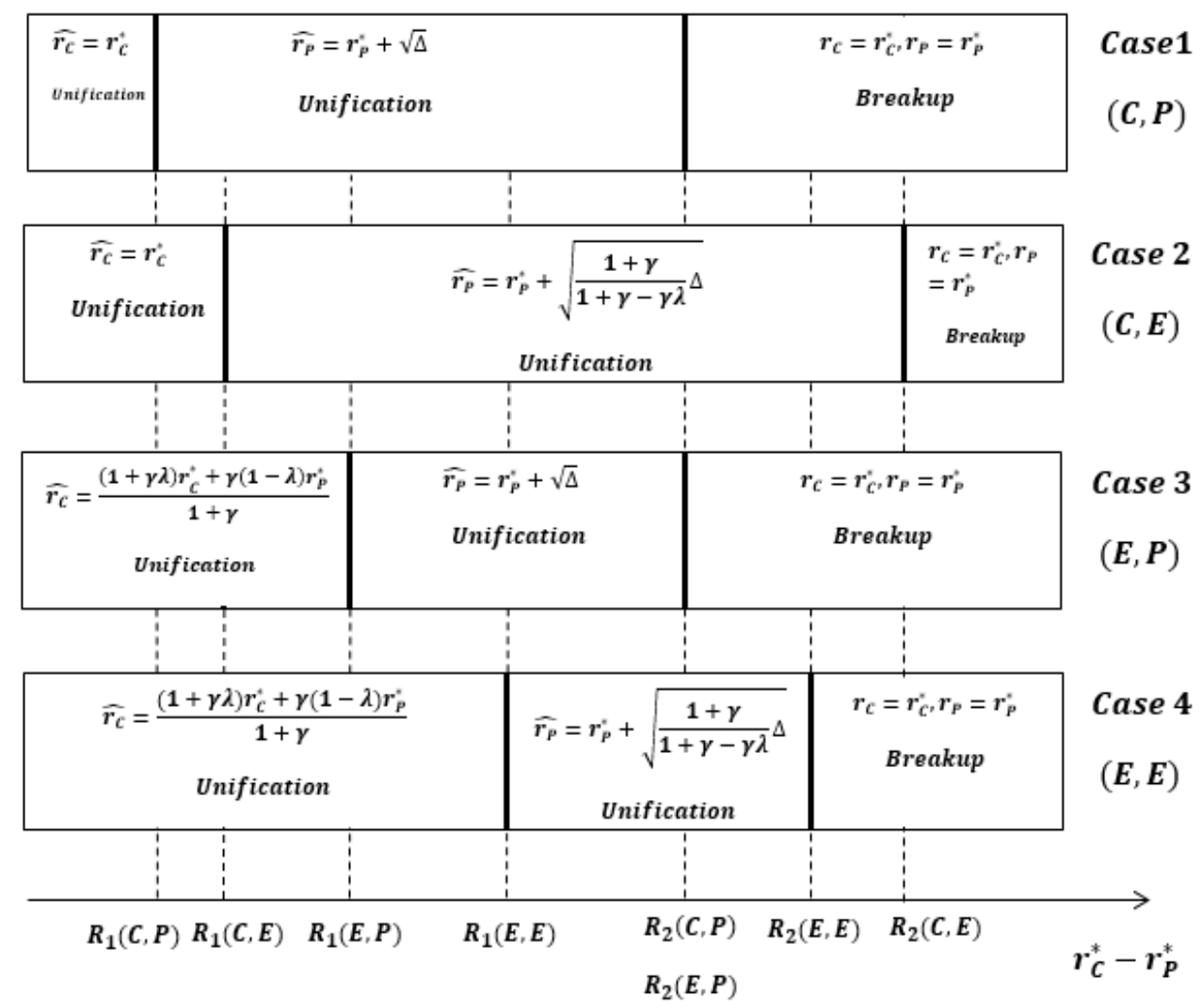

Figure 6: SPNE under Different Social Identity Profiles

Note: The figure is drawn for the case where $R_{1}(C, E)<R_{1}(E, P)$ and $R_{1}(E, E)<R_{2}(E, E)$.

Furthermore, the Periphery's identity allows the union to be sustained with lower concessions in the intermediate range between $R_{1}$ and $R_{2}$ (i.e union is less accommodating) which in turn makes the union more robust under the $(E, E)$ profile than under either the $(C, P)$ or $(E, P)$ profiles.

Interestingly, $R_{2}(E, E)<R_{2}(C, E)$ : the union is less robust when everyone identifies with Europe than when only the Periphery does. Essentially, when the Core identifies with Europe, it takes into account the fact that when fundamental differences between the countries are sufficiently large, the Periphery would be better off outside the union, conducting its own policy. These considerations do not arise when the Core identifies with own country, and the union is sustained at the Periphery's expense.

A summary of the four cases (for certain parameter values) is in Figure 6. 


\subsection{Is unification optimal from a material-payoff maximizing per- spective?}

Robustness is not necessarily a good thing. If differences are large, the countries may be better off splitting. A natural approach to evaluating the welfare properties of the SPNE under different identities, is to compare them to what a social planner interested in maximizing aggregate material payoffs would do. Let $V_{E}\left(r_{C}, r_{P}\right.$, breakup $)=\lambda V_{C}\left(r_{C}\right.$, breakup $)+$ $(1-\lambda) V_{P}\left(r_{P}\right.$, breakup $)$ be the aggregate material payoff.

Definition 4. A union is materially optimal if it is sustained if and only if $\max _{r_{C}, r_{P}} V_{E}\left(r_{C}, r_{P,} 0\right) \geq$ $\max _{r_{C}, r_{P}} V_{E}\left(r_{C}, r_{P, 1}\right)$.

\section{Proposition 4. Material Optimality and Robustness.}

a. When the Periphery identifies with the nation the union is not materially optimal, regardless of Core identity. The union is less robust than what an aggregate-material-payoff maximizer would choose.

b. When the Periphery identifies with Europe, then for any Core identity the union may or may not be materially optimal. If $\lambda$ is sufficiently small the union is more robust than what an aggregate-material-payoff maximizer would choose.

Thus, there exists a range of fundamental differences $r_{C}^{*}-r_{P}^{*}$ for which it would be optimal to form a union, and yet if the individuals in the Periphery identify with their nation then the union cannot be sustained. This does not depend on Core identity. Thus, if the union is clearly desirable from a material payoff prospective, achieving unification requires reinforcement of European identity in the Periphery, not in the Core.

A common identity, however, does not always enhance overall material payoffs. There exist situations where it is materially optimal to dismantle the union, and yet if the Periphery identifies with Europe the union is sustained nonetheless. This result complements Alesina and Spolaore's (1997) result that under democracy nations tend to be too small. We obtain a similar result when individuals identify with their own nations, but not necessarily when they identify with larger units. The basic reason, again, is that when the Periphery identifies with Europe, the union is sustained at the expense of the Periphery's material payoff. This could be optimal if the Periphery is relatively small ( $\lambda$ large) but when the Periphery is large, this implies a high aggregate cost. 


\section{Choice of Social Identity}

We now turn to the determination of social identity itself. Assume that individual $i$ chooses to identify with group $j$ rather than with group $j^{\prime}$ if identifying with the former yields higher utility. This is consistent with extensive evidence showing that individuals are more likely to identify with groups that have higher status (discussed in the introduction). Note however, that status is endogenous since it depends, at least partly, on material payoffs which in turn depend on the enacted policy. Thus, an appropriate concept of equilibrium is required. It is useful, however, to first delineate the choice of identity as a function of the (ex-post) status gap between the two countries, $S_{C}-S_{P}$, for a given policy. ${ }^{8}$

An individual from country $i$ chooses identity $j$ to solve:

$$
\max _{j \in\{i, E\}} U_{i j}\left(r_{C}, r_{P}, \text { breakup }\right)
$$

Thus, an individual in the Core country identifies with her own country if $U_{C C}>U_{C E}$. Recall from equation (2) that $U_{i j}=V_{i}+\gamma S_{j}$. For any given policy, own material payoff $V_{i}$ does not depend on the choice of identity. Hence identification with own country occurs if $S_{C}>S_{E}$. Using equations (3) and (4) this condition can be written as:

$$
S_{C}-S_{P}>\sigma_{C}-\sigma_{P}+\frac{\sigma_{E}-\sigma_{C}}{1-\lambda}
$$

In other words, the Core individual identifies with her own country when the status gap between the two countries is sufficiently high. This is more likely to occur when the exogenous (or ex-ante) sources of Core status, captured by $\sigma_{C}$, are high while those of Europe $\left(\sigma_{E}\right)$ are low. Similarly, a Periphery individual identifies with her own country if:

$$
S_{C}-S_{P}<\sigma_{C}-\sigma_{P}+\frac{\sigma_{P}-\sigma_{E}}{\lambda}
$$

Figure 7 illustrates how the identity profile is determined as a function of the ex-post status gap $S_{C}-S_{P}$. It will be convenient to continue having the fundamental differences on the horizontal axis. Dashed lines represent "identity indifference curves". In the simplest case (leftmost panel), $\sigma_{E}$ equals the population-weighted average of $\sigma_{P}$ and $\sigma_{C}$. In this case, if ex-post Core status is higher than the Periphery's, then the only possible identity profile is $(C, E)$. Conversely if $S_{C}<S_{P}$ the only possible profile is $(E, P)$. If $S_{C}=S_{P}$ then both Core

\footnotetext{
${ }^{8}$ In general, the status gap will be a function of the fundamental differences between the countries, and the policies chosen given these differences. The status gap functions are made explicit in Appendix A.5.
} 


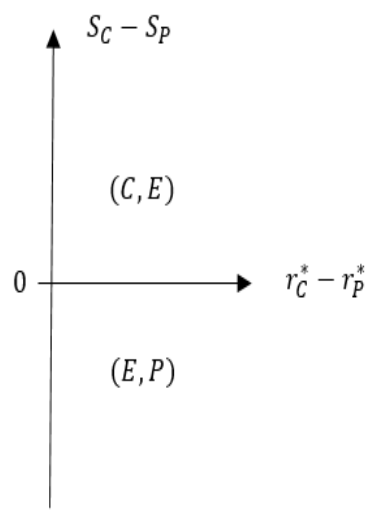

A. Average European Status $\sigma_{E}=\lambda \sigma_{C}+(1-\lambda) \sigma_{P}$

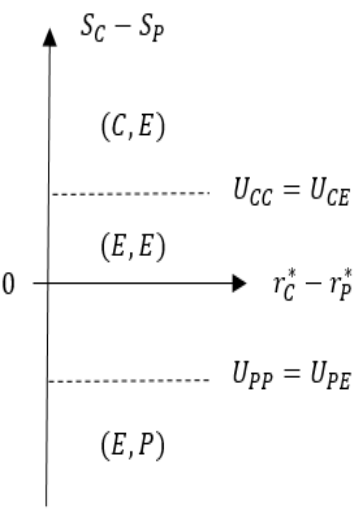

B. High European Status $\sigma_{E}>\lambda \sigma_{C}+(1-\lambda) \sigma_{P}$

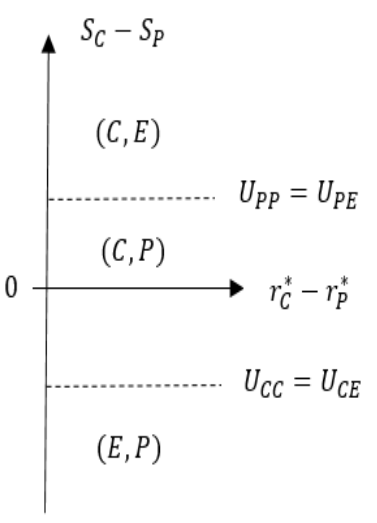

C. Low European Status $\sigma_{E}<\lambda \sigma_{C}+(1-\lambda) \sigma_{P}$

Figure 7: Choice of Social Identity

and Periphery individuals are indifferent and hence all four identity profiles are possible. The situation is slightly more nuanced when ex-ante European status is different from this benchmark. If it is higher (middle panel), there now exists an intermediate range where both the Core and the Periphery identify with Europe. Note that in this case, the $(C, P)$ profile cannot be sustained. If ex-ante European status is lower (rightmost panel), there exists an intermediate range where both the Core and the Periphery identify with their nation, and the $(E, E)$ profile cannot be sustained.

\section{$5 \quad$ Social Identity Equilibrium}

We now ask what configurations of social identities and policies are likely to hold in equilibrium, when both are endogenously determined. The basic idea can be illustrated using Figure 7. The analysis in Section 3 allows us to derive the status gap as a function of the fundamental differences between the countries, for each profile of identities. However, some of these profiles would not in fact be chosen, as the status gap would not lie in the corresponding region. We thus propose a concept of a Social Identity Equilibrium (SIE), based on Shayo (2009). SIE requires not only that the policies implemented in both countries be a SPNE given the social identity profile, but also that the social identities themselves be optimal given these policies. Formally: 
Definition 5. A Social Identity Equilibrium (SIE) is a profile of policies $\left(r_{C}, r_{P}\right.$, breakup) and a profile of social identities $\left(I D_{c}, I D_{p}\right)$ such that:

i. $\left(r_{C}, r_{P}\right.$, breakup $)$ is the outcome of a SPNE given the profile of social identities $\left(I D_{c}, I D_{p}\right)$

ii. $I D_{i}=\underset{I D_{i} \in\{i, E\}}{\operatorname{argmax}} U_{i, I D_{i}}\left(r_{C}, r_{P}\right.$, breakup $)$ for all $i \in\{C, P\}$.

We begin our analysis with a benchmark case of no ex-ante status differences between the countries and Europe. We then turn to two natural cases. The first, which could correspond to the Greek-and-the-Eurozone case, is the one in which the Periphery has ex-ante low status. The second, which could correspond to the UK-and-the-EU case, is the reverse, where the Periphery has high status.

Proposition 5. When there are no ex-ante differences in status, i.e. $\sigma_{C}=\sigma_{P}=\sigma_{E}$ then:

a. An SIE exists.

b. In almost any SIE in which the union is sustained, the social identity profile is $(C, E)$. The only exceptions are when $r_{C}^{*}=r_{P}^{*}$ and when $r_{C}^{*}-r_{P}^{*}=R_{2}(C, P)$; in these cases other identity profiles can also be sustained under unification.

c. When fundamental differences are smaller than $R_{2}(C, P)$, SIE implies unification. When fundamental differences are larger than $R_{2}(C, E)$, SIE implies breakup. For fundamental differences between $R_{2}(C, P)$ and $R_{2}(C, E)$, both unification and breakup can occur in SIE.

d. The profile $(E, E)$ can be sustained either when fundamental differences are zero or under breakup and large fundamental differences.

The main flavor of this Proposition is illustrated in Figure 8. The solid curve shows the status gap in the SPNE under the $(C, E)$ profile. At any level of fundamental differences below $R_{2}(C, E)$, the status gap is above the identity indifference curve. Hence, the $(C, E)$ profile is indeed chosen by individuals in the Core and the Periphery. Thus, for any level of fundamental differences in this range, there exists an SIE with unification and $(C, E)$. It can also be shown that the SPNE for all other identity profiles imply a status gap which is strictly above the identity indifference curve, for all fundamental differences greater than zero and below the respective $R_{2}$ 's. Thus, if unification is sustained in SPNE, the identity profile cannot be an equilibrium. If fundamental differences are above the relevant $R_{2}$, the status gap is zero and the profile can be sustained in SIE, but since differences are above $R_{2}$ the SPNE involves breakup. The proof provides more details. 


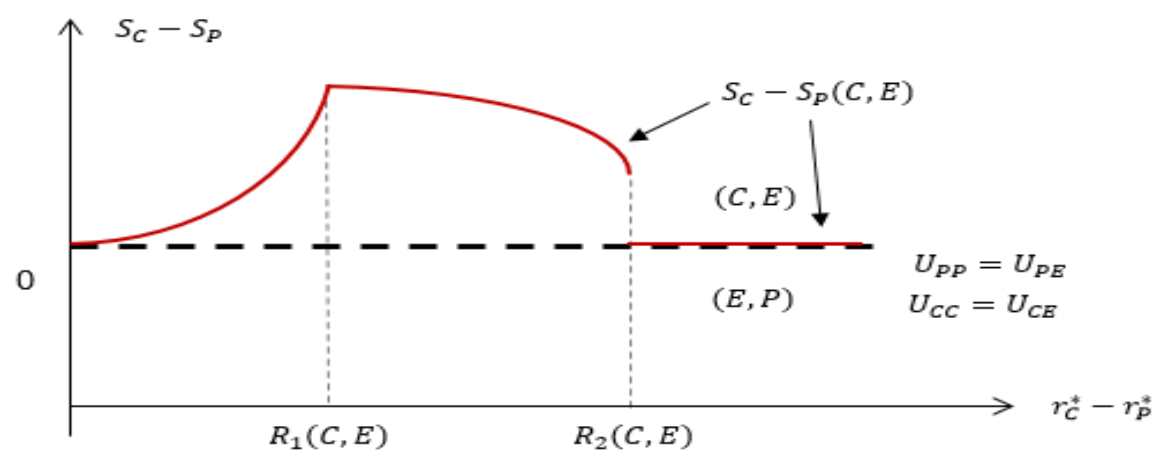

Figure 8: SIE under No Ex-Ante Differences in Status

Proposition 5 complements our result in Corollary 1. Not only is the union most robust when the social identity profile is $(C, E)$, this is the unique social identity profile that holds in any SIE in which the union is sustained, except for very special cases. It is also interesting to note that, given large fundamental differences between the countries, the "benign" allEuropean identity profile can only be sustained in SIE under breakup.

Next, consider the SIE when the ex-ante status of the Periphery is lower than the Core's.

Proposition 6. When the Core has ex-ante higher status, and the Periphery has ex-ante lower status than Europe, i.e. $\sigma_{C}>\sigma_{E}>\sigma_{P}$, then there exists a unique SIE. Furthermore the social identity profile is $(C, E)$, and the union is sustained if and only if fundamental differences are smaller than $R_{2}(C, E)$.

Recall from Proposition 5 that when $\sigma_{C}=\sigma_{P}=\sigma_{E}$, there exists a range of fundamental differences in which both unification and breakup can take place in SIE. Proposition 6 implies that differences in ex-ante status can push the countries towards a unique SIE in which unification occurs. Thus, when the Periphery has lower ex-ante status the union can be sustained in SIE under higher levels of fundamental differences. Note that in effect the union is sustained at the expense of the Periphery's material payoff. When Periphery members identify with Europe and Core members identify with their nation, the union is least accommodating (Proposition 3). As a result, the status gap $\left(S_{C}-S_{P}\right)$ between the Core and the Periphery widens, and members of the Core identify with their nation while members of the (worse-off) Periphery are motivated to indeed identify with Europe. This in turn allows the Core to systematically implement a less accommodating policy for the union.

This process can help understand both the strained relationship between Germany and Greece as well as Greece's continued membership in the Eurozone. Significant fundamental differences between the countries have not led to a "Grexit" from the Eurozone, despite the 
grave recession in Greece following the outbreak of the European debt crises. Moreover, the core Euro countries were able to demand - and the Greek government accepted - severe austerity measures in order to remain part of the Eurozone, even though many economists were skeptical regarding the economic benefits. Indeed, as the model suggests, the dismal economic performance of Greece may have itself helped sustain the relatively high levels of European identification in Greece, seen in Figure 1.

It is interesting to note that an SIE with the social identity profile $(E, E)$ cannot be sustained when $\sigma_{C}>\sigma_{E}>\sigma_{P}$. This works in the opposite direction to that emphasized by proponents of an "ever-closer union" who argue that joining the union itself ultimately brings the member countries closer together (see discussion in Spolaore, 2015). In this case, despite the union being very robust - and to some degree because of its robustness - Core countries tend towards more national identities and the union is not very accommodating to the needs of the Periphery.

Finally, consider the Social Identity Equilibrium when the ex-ante status of the Periphery is higher than the Core's.

Proposition 7. When the Periphery has ex-ante higher status and the Core has ex-ante lower status than Europe, i.e. $\sigma_{C}<\sigma_{E}<\sigma_{P}$, then:

a. An SIE exists.

b. Breakup can occur when fundamental differences are smaller than $R_{2}(C, E)$.

c. In any SIE in which breakup occurs, the social identity profile is $(E, P)$.

d. There exists an intermediate range of fundamental differences in which both unification and breakup can occur. However, in any SIE in this range in which unification occurs, the Periphery identifies with the union.

e. The profile $(E, E)$ can be sustained only if fundamental differences between the countries are at some intermediate range.

Three lessons are worth highlighting. First, the union is more fragile in this case. In contrast to the previous case, in which unification necessarily occurs as long as fundamental differences are below a certain threshold $\left(R_{2}(C, E)\right)$, in the case when the Periphery has higher ex-ante status, breakup can also occur below this threshold. This is illustrated in Figure 9 (Panel A). The figure depicts the status gap curve under $(E, P)$. When this curve lies below both the $U_{P P}=U_{P E}$ and the $U_{C C}=U_{C E}$ identity indifference curves, the $(E, P)$ profile holds in SIE. In particular, note that for fundamental differences above $R_{2}(E, P)$ the SIE involves breakup. 

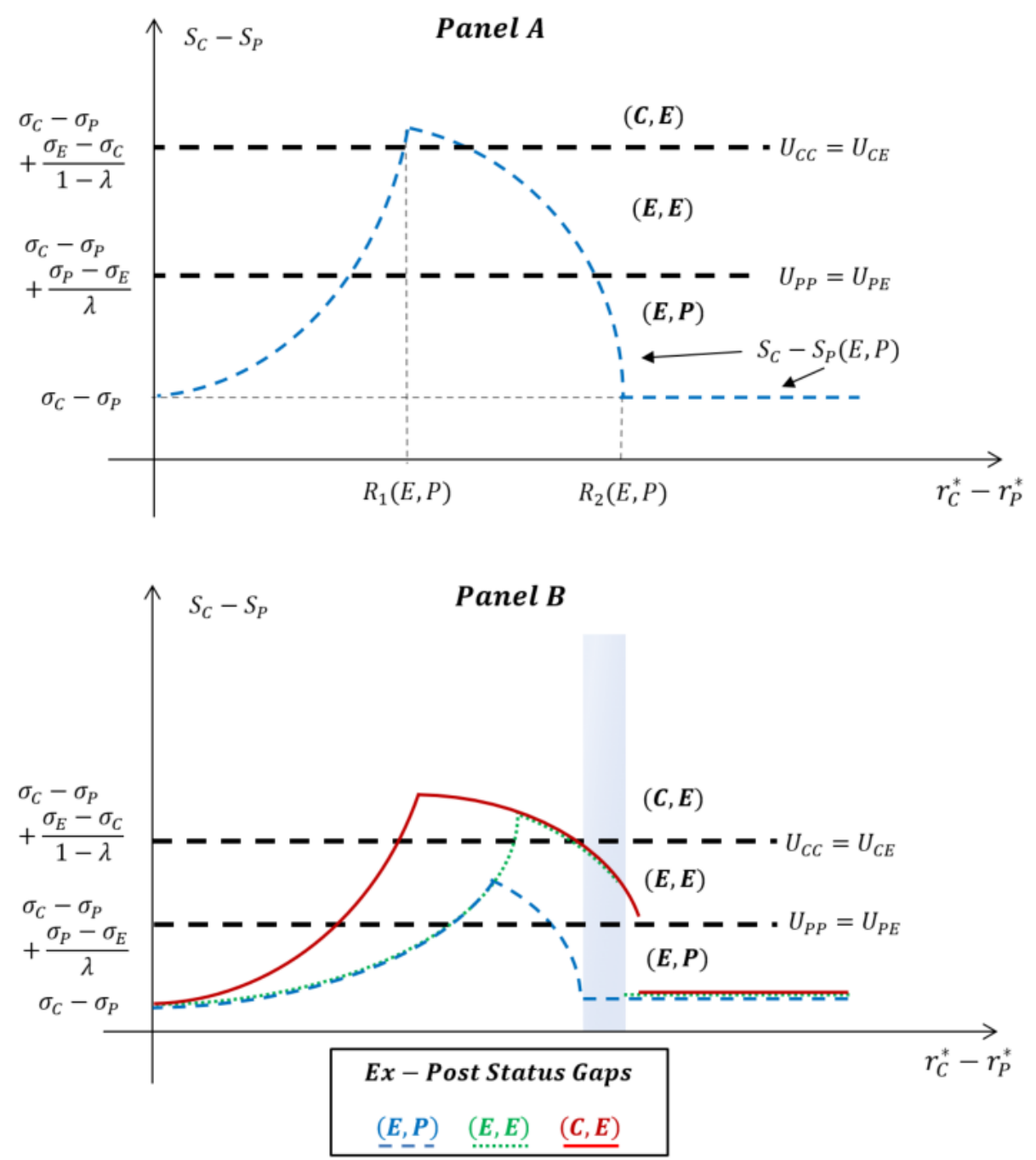

Figure 9: SIE when the Periphery has Higher Ex-Ante Status Note: the Figure is drawn for the case in which $\sigma_{E}>\lambda \sigma_{C}+(1-\lambda) \sigma_{P}$.

But we know from Section 3 that $R_{2}(E, P)<R_{2}(C, E)$. The upshot is that it is harder to sustain a union when the Periphery has higher status, because the status differences make it harder to sustain an identity profile that can support unification in the face of differences between the countries.

Second, consider levels of fundamental differences such that multiple SIE exist with some involving breakup and others involving unification. Proposition 7 says that any SIE in this region that involve unification must have the Periphery identify with Europe. This can be seen in Figure 9, Panel B. The figure depicts the status gap functions under three identity profiles. ${ }^{9}$ Note that at various levels of fundamental differences, multiple equilibria can exist,

\footnotetext{
${ }^{9}$ The figure is drawn for the case when European status is high, hence $(C, P)$ can never be part of an
} 
with different identity profiles. In particular, the shaded area shows a region of fundamental differences in which there exists an SIE with breakup and the Periphery identifying nationally (the $(E, P)$ profile - dashed blue curve). For the same levels of fundamental differences, there also exist SIE's with unification but in all these SIE's the Periphery identifies with Europe (the $(E, E)$ profile - green dotted curve; and the $(C, E)$ profile - solid red curve).

Third, as Figure 9 also illustrates, in any SIE where breakup occurs, the identity profile has the Core identifying with Europe and the Periphery identifying nationally. In the European case, this suggests that if a Brexit indeed takes place, it would tend to reinforce national identification in the UK, and European identification in the Core north European countries.

This case can also help shed light on the composition of the Euro-zone. The UK, as well as other relatively high-status countries like Sweden and Denmark, have continuously rejected the adoption of the Euro, despite arguably being more similar and more closely connected to the dominant German economy than other countries that ended up joining, like Spain, Portugal and Greece. And as illustrated in Figure 1, the British population strongly identifies with its nation rather than with Europe. This national sense of identification seems much stronger in the UK than in most countries in the EU.

\section{Summary and Concluding Remarks}

Social identity has been widely discussed as an important factor underlying economic and political integration. While it is often taken for granted that national identities are detrimental to integration whereas a common identity promotes it, our analysis suggests a more nuanced view. A union may be most robust, not when everyone identifies with the union, but when individuals from the Core countries identify with their country, while individuals from the Periphery identify with the union as a whole. Notably, this profile of social identities also yields the least accommodating union. In terms of material payoffs, such a union is sustained at the expense of the Periphery country.

Taking into consideration that identities might adjust to economic conditions, we propose a concept of Social Identity Equilibrium (SIE) in which both policies and identities are endogenously determined. A central finding is that, other things equal, a union with low (ex-ante) status periphery countries can be sustained in SIE under larger fundamental differences than a union with (ex-ante) high-status periphery countries. Furthermore, unification does not necessarily support the emergence of a common identity. Indeed, in the case

equilibrium and we do not show the status gap curve under this profile. The intuition for the result is similar in the case when European status is low. 
of relatively high Core status, integration would tend to push the Core countries towards a more exclusionary identity.

Two final remarks concern empirical and theoretical extensions. The paper points to several challenges for empirical work. A preliminary issue is correctly measuring social identities. The survey measures of identification we have used in the introduction need to be interpreted with care. Furthermore, these data do not provide us with clean measures of identification with the Core (which in the European case includes more than one nationality), and might not provide a consistent measure of identification with the union as a whole: while for Greeks "Europe" probably includes Germany, for Germans, thinking about "Europe" in the context of the survey may not invoke Greece as a prominent component. At a more substantive level, the main challenge is finding exogenous variation in identification patterns to evaluate the results in Section 3; as well as exogenous shocks to integration and to national status to evaluate the mechanisms in Section 5. While challenging, recent studies suggest potentially feasible avenues (see Dehdari and Gehring, 2017, and Michalopoulos and Papaioannou, 2016, on border shocks; and Depetris-Chauvin and Durante, 2017, on status shocks and ethnic identity).

On the theory side, the model we studied here takes fundamental differences between countries as fixed. This is a natural first step. However, it seems reasonable to suspect that in the long run, fundamental differences between countries may themselves be endogenous to both integration and identification choices. The evidence here is mixed. Since the 1980's, there appears to have been some economic convergence across EU countries (at least until the financial crisis). However, there is little evidence that EU countries have become more similar in fundamental values or in major institutional features (Alesina, Tabellini and Trebbi, 2017). This, however, might partly reflect the fact that integration does not necessarily promote the emergence of a common identity (hence the effects of integration and social identities may cancel out). Studying the long run equilibrium, where fundamental differences themselves respond to social identities may thus prove particularly useful. 


\section{References}

Akerlof, George A, and Rachel E Kranton. 2000. "Economics and Identity." The Quarterly Journal of Economics, 115(3): 715-753.

Akerlof, George A, and Rachel E Kranton. 2010. Identity Economics: How Identities Shape Our Work, Wages, and Well-Being. Princeton, NJ: Princeton University Press.

Alesina, Alberto, and Enrico Spolaore. 1997. "On the Number and Size of Nations." The Quarterly Journal of Economics, 112(4): 1027-1056.

Alesina, Alberto, Enrico Spolaore, and Romain Wacziarg. 2005. "Trade, Growth and the Size of Countries." Handbook of economic growth, 1: 1499-1542.

Alesina, Alberto, Guido Tabellini, and Francesco Trebbi. 2017. "Is Europe an optimal political area?" National Bureau of Economic Research, Working Paper 23325.

Alesina, Alberto, Robert J Barro, and Silvana Tenreyro. 2002. "Optimal Currency Areas." NBER Macroeconomics Annual, 17: 301-345.

Bechtel, Michael M, Jens Hainmueller, and Yotam Margalit. 2014. "Preferences for International Redistribution: The Divide over the Eurozone Bailouts." American Journal of Political Science, 58(4): 835856 .

Becker, Sascha O, Thiemo Fetzer, and Dennis Novy. 2017. "Who Voted for Brexit? A Comprehensive District-Level Analysis." Economic Policy, Forthcoming.

Bénabou, Roland, and Jean Tirole. 2011. "Identity, morals, and taboos: Beliefs as assets." The Quarterly Journal of Economics, 126(2): 805-855.

Benjamin, Daniel J, James J Choi, and A Joshua Strickland. 2010. "Social Identity and Preferences." The American Economic Review, 100(4): 1913-1928.

Bettencourt, B, Kelly Charlton, Nancy Dorr, and Deborah L Hume. 2001. "Status differences and in-group bias: a meta-analytic examination of the effects of status stability, status legitimacy, and group permeability." Psychological Bulletin, 127(4): 520.

Bisin, Alberto, and Thierry Verdier. 2001. "The economics of cultural transmission and the dynamics of preferences." Journal of Economic Theory, 97(2): 298-319.

Bolton, Patrick, and Gerard Roland. 1997. "The breakup of nations: a political economy analysis." The Quarterly Journal of Economics, 112(4): 1057-1090.

Carvalho, Jean-Paul. 2013. "Veiling." The Quarterly Journal of Economics, 128(1): 337-370.

Chandra, Kanchan. 2012. Constructivist Theories of Ethnic Politics. Oxford University Press. 
Chen, Yan, and Sherry Xin Li. 2009. "Group identity and social preferences." The American Economic Review, 99(1): 431-457.

Cialdini, Robert B, Richard J Borden, Avril Thorne, Marcus Randall Walker, Stephen Freeman, and Lloyd Reynolds Sloan. 1976. "Basking in reflected glory: Three (football) field studies." Journal of Personality and Social Psychology, 34(3): 366.

De Grauwe, Paul. 2014. Economics of monetary union. Oxford University Press.

Dehdari, Sirus, and Kai Gehring. 2017. "The origins of common identity: Division, homogenization policies and identity formation in Alsace-Lorraine." Working Paper.

Den Haan, Wouter, Martin Ellison, Ethan Ilzetzki, Michael McMahon, and Ricardo Reis. 2016. "Brexit and the economics profession: Are academic economists out of touch with voters and politicians?" voxeu.org/article/cfm-survey-july-2016-brexit-and-economics-profession.

Depetris-Chauvin, Emilio, and Ruben Durante. 2017. "One team, one nation: Football, ethnic identity, and conflict in Africa." Working Paper.

Donaldson, Dave. 2015. "The Gains from Market Integration." Annual Review of Economics, 7: 619-647.

Ellemers, Naomi, Paulien Kortekaas, and Jaap W Ouwerkerk. 1999. "Self-categorisation, commitment to the group and group self-esteem as related but distinct aspects of social identity." European Journal of Social Psychology, 29(23): 371-389.

Feldstein, Martin. 1997. "The political economy of the European economic and monetary union: Political sources of an economic liability." The Journal of Economic Perspectives, 11(4): 23.

Guiso, Luigi, Paola Sapienza, and Luigi Zingales. 2006. "Does culture affect economic outcomes?" The Journal of Economic Perspectives, 20(2): 23-48.

Guiso, Luigi, Paola Sapienza, and Luigi Zingales. 2009. "Cultural Biases in Economic Exchange?" The Quarterly Journal of Economics, 1095-1131.

Hooghe, Liesbet, and Gary Marks. 2004. "Does Identity or Economic Rationality Drive Public Opinion on European Integration?" PS: Political Science and Politics, 37(3): 415-420.

Hooghe, Liesbet, and Gary Marks. 2009. "A Postfunctionalist Theory of European integration: From Permissive Consensus to Constraining Dissensus." British Journal of Political Science, 39(01): 1-23.

Mayda, Anna Maria, and Dani Rodrik. 2005. "Why are some people (and countries) more protectionist than others?" European Economic Review, 49(6): 1393-1430.

Maystre, Nicolas, Jacques Olivier, Mathias Thoenig, and Thierry Verdier. 2014. "Product-based cultural change: Is the village global?" Journal of International Economics, 92(2): 212-230.

Michalopoulos, Stelios, and Elias Papaioannou. 2016. "The long-run effects of the scramble for Africa." The American Economic Review, 106(7): 1802-1848. 
Mundell, Robert A. 1961. "A Theory of Optimum Currency Areas." The American Economic Review, 51(4): 657-665.

Roccas, Sonia. 2003. "The effects of status on identification with multiple groups." European Journal of Social Psychology, 33(3): 351-366.

Sambanis, Nicholas, Jonah Schulhofer-Wohl, and Moses Shayo. 2012. "Parochialism as a central challenge in counterinsurgency." Science, 336(6083): 805-808.

Schuman, Robert. 1950. "The Schuman Declaration. 9 May."

Serricchio, Fabio, Myrto Tsakatika, and Lucia Quaglia. 2013. "Euroscepticism and the Global Financial Crisis." JCMS: Journal of Common Market Studies, 51(1): 51-64.

Shayo, Moses. 2009. "A Model of Social Identity with an Application to Political Economy: Nation, Class, and Redistribution." American Political Science Review, 103(02): 147-174.

Shayo, Moses, and Asaf Zussman. 2011. "Judicial ingroup bias in the shadow of terrorism." The Quarterly Journal of Economics, 126(3): 1447-1484.

Shayo, Moses, and Asaf Zussman. 2017. "Conflict and the Persistence of Ethnic Bias." American Economic Journal: Applied Economics, forthcoming.

Spolaore, Enrico. 2015. "The Political Economy of European Integration." National Bureau of Economic Research, Working Paper 21250.

Spolaore, Enrico, and Romain Wacziarg. 2013. "How deep are the roots of economic development?" Journal of Economic Literature, 51(2): 325-369.

Stokes, Bruce. 2016. "Euroskepticism beyond Brexit." Pew Research Center, June 7.

Tabellini, Guido. 2008. "Presidential address: institutions and culture." Journal of the European Economic Association, 6(2-3): 255-294.

Van Klingeren, Marijn, Hajo G Boomgaarden, and Claes H De Vreese. 2013. "Going soft or staying soft: have identity factors become more important than economic rationale when explaining euroscepticism?" Journal of European Integration, 35(6): 689-704.

Voigtländer, Nico, and Hans-Joachim Voth. 2012. "Persecution perpetuated: the medieval origins of anti-Semitic violence in Nazi Germany." The Quarterly Journal of Economics, 127(3): 1339-1392. 


\section{Appendix}

\section{A Proofs}

\section{A.1 Proof of Lemmas 1-4 and Proposition 1:}

We provide here the detailed proof for the case in which both Core and Periphery identify nationally. For convenience we reproduce the relevant utilities from equations (5) and (6):

$$
\begin{aligned}
& U_{C C}=\gamma \sigma_{C}-(1+\gamma)\left[\left(r_{C}-r_{C}^{*}\right)^{2}+\Delta * \text { breakup }\right] \\
& U_{P P}=\gamma \sigma_{P}-(1+\gamma)\left[\left(r_{P}-r_{P}^{*}\right)^{2}+\Delta * \text { breakup }\right]
\end{aligned}
$$

Note that the Periphery's utility depends on whether it accepts or rejects $r_{C}$. If it rejects, it sets its policy optimally to $r_{P}^{*}$. Hence:

$$
U_{P P}= \begin{cases}-(1+\gamma)\left(r_{C}-r_{P}^{*}\right)^{2}+\gamma \sigma_{P} & \text { if } P \text { accepts } \\ -(1+\gamma) \triangle+\gamma \sigma_{P} & \text { if } P \text { rejects }\end{cases}
$$

Clearly, for $r_{C} \geq r_{P}^{*}$ the Periphery accepts $r_{C}$ if and only if $r_{C}-r_{P}^{*} \leq \sqrt{\triangle} \equiv R_{1}(C, P)$. Since the Core identifies nationally, its chosen policy when there is no threat of secession is $r_{C}^{*}$, which we denote by $\widehat{r}_{C}(C, P)$. Thus, when $r_{C}^{*}-r_{P}^{*} \leq R_{1}(C, P)$ the Core is indeed able to set its policy to $r_{C}^{*}$ without suffering the cost of breakup.

When $r_{C}^{*}-r_{P}^{*}>R_{1}(C, P)$, the Core decides between the following two options:

1. Set the policy that maximizes utility under breakup, which is $r_{C}^{*}$. Utility will then be:

$$
\left.U_{C C}\right|_{\text {breakup }}=-(1+\gamma) \triangle+\gamma \sigma_{C}
$$

2. Set the policy that maximizes utility subject to the constraint that the union is sustained (i.e choose among the policies that would be accepted by the Periphery). This policy is $r_{C}=\min \left\{r_{C}^{*}, r_{P}^{*}+\sqrt{\triangle}\right\}=r_{P}^{*}+\sqrt{\triangle}$, since $r_{C}^{*}-r_{P}^{*}>\sqrt{\triangle}$ in this case. Denote this policy by $\widehat{r}_{P}(C, P)$. Utility is then:

$$
\left.U_{C C}\right|_{\text {unification }}=-(1+\gamma)\left(r_{P}^{*}-r_{C}^{*}+\sqrt{\triangle}\right)^{2}+\gamma \sigma_{C}
$$

Since $r_{C}^{*}-r_{P}^{*}>\sqrt{\triangle}$, we have $\left.U_{C C}\right|_{\text {breakup }}>\left.U_{C C}\right|_{\text {unification }}$ if and only if $r_{C}^{*}-r_{P}^{*}>$ 
$2 \sqrt{\triangle} \equiv R_{2}(C, P)$.

In summary, the SPNE for the $(C, P)$ social identity profile is given by:

1. if $r_{C}^{*}-r_{P}^{*} \leq R_{1}(C, P)$ unification occurs and $r_{C}=r_{P}=\widehat{r}_{C}(C, P)$.

2. if $R_{1}(C, P)<r_{C}^{*}-r_{P}^{*} \leq R_{2}(C, P)$ unification occurs and $r_{C}=r_{P}=\widehat{r}_{P}(C, P)$.

3. if $r_{C}^{*}-r_{P}^{*}>R_{2}(C, P)$ breakup occurs and $r_{C}=r_{C}^{*}, r_{P}=r_{P}^{*}$.

Finally, we have that $R_{1}(C, P)<R_{2}(C, P), \widehat{r}_{P}(C, P)<\widehat{r}_{P}(C, P)$ and that both $R_{1}(C, P)$ and $R_{2}(C, P)$ are strictly increasing functions of the breakup cost $\triangle$.

To characterize the SPNE for the remaining social identity profiles, apply the same steps, using the relevant utility functions from equations (5)-(8). This yields Lemmas 2-4. From Lemmas 1-4 we obtain Proposition 1.

\section{A.2 Proof of Proposition 2:}

From Lemmas 1-4 and some algebra it is easy to show:

$a$.

1. $R_{2}(C, P)=R_{2}(E, P)$

2. $R_{2}(C, E)>R_{2}(E, E)$

$b$.

1. $R_{2}(C, E)>R_{2}(C, P)$

2. $R_{2}(E, E)>R_{2}(E, P)$.

\section{A.3 Proof of Proposition 3:}

a. From Lemmas 1,3 we obtain:

1. $r_{P}^{*} \leq \widehat{r}_{c}(E, P) \leq \widehat{r}_{c}(C, P)$ for any given level of fundamental differences such that $r_{C}^{*}-r_{P}^{*}<\min \left\{R_{1}(C, P), R_{1}(E, P)\right\}=R_{1}(C, P)$;

2. $r_{P}^{*}<\widehat{r}_{c}(E, P) \leq \widehat{r}_{p}(C, P)$ for $R_{1}(C, P)<r_{C}^{*}-r_{P}^{*} \leq R_{1}(E, P)$;

3. $r_{P}^{*}<\widehat{r}_{p}(E, P)=\widehat{r}_{p}(C, P)$ for $R_{1}(E, P)<r_{C}^{*}-r_{P}^{*} \leq \min \left\{R_{2}(C, P), R_{2}(E, P)\right\}=$ $R_{2}(C, P)=R_{2}(E, P)$.

Hence the union is more accommodating in the $(E, P)$ than in the $(C, P)$ case. From Lemmas 2,4 and simple algebra we obtain: 
4. $r_{P}^{*} \leq \widehat{r}_{c}(E, E)<\widehat{r}_{c}(C, E)$ for $r_{C}^{*}-r_{P}^{*}<\min \left\{R_{1}(C, E), R_{1}(E, E)\right\}=R_{1}(C, E)$;

5. If $R_{1}(E, E)<R_{2}(E, E)$ then:

(a) $r_{P}^{*}<\widehat{r}_{c}(E, E) \leq \widehat{r}_{p}(C, E)$ for $R_{1}(C, E)<r_{C}^{*}-r_{P}^{*} \leq R_{1}(E, E)$

(b) $r_{P}^{*}<\widehat{r}_{p}(E, E)=\widehat{r}_{p}(C, E)$ for $R_{1}(E, E)<r_{C}^{*}-r_{P}^{*} \leq \min \left\{R_{2}(C, E), R_{2}(E, E)\right\}=$ $R_{2}(E, E)$

6. If $R_{1}(E, E)=R_{2}(E, E)$ then $r_{P}^{*}<\widehat{r}_{c}(E, E) \leq \widehat{r}_{p}(C, E)$ for $R_{1}(C, E)<r_{C}^{*}-r_{P}^{*} \leq$ $\min \left\{R_{2}(C, E), R_{2}(E, E)\right\}=R_{2}(E, E)$.

Hence the union is more accommodating in the $(E, E)$ than in the $(C, E)$ case. This proves part $a$ of the proposition.

b. Similarly, from Lemmas 3,4:

1. $r_{P}^{*} \leq \widehat{r}_{c}(E, P)=\widehat{r}_{c}(E, E)$ for $r_{C}^{*}-r_{P}^{*}<\min \left\{R_{1}(E, P), R_{1}(E, E)\right\}=R_{1}(E, P)$

2. If $R_{1}(E, E) \leq R_{2}(E, P)$ then:

(a) $r_{P}^{*}<\widehat{r}_{p}(E, P) \leq \widehat{r}_{c}(E, E)$ for $R_{1}(E, P)<r_{C}^{*}-r_{P}^{*} \leq R_{1}(E, E)$

(b) $r_{P}^{*}<\widehat{r}_{p}(E, P)<\widehat{r}_{p}(E, E)$ for $R_{1}(E, E)<r_{C}^{*}-r_{P}^{*} \leq \min \left\{R_{2}(E, P), R_{2}(E, E)\right\}=$ $R_{2}(E, P)$

3. If $R_{1}(E, E)>R_{2}(E, P)$ then $r_{P}^{*}<\widehat{r}_{p}(E, P) \leq \widehat{r}_{c}(E, E)$ for $R_{1}(E, P)<r_{C}^{*}-r_{P}^{*} \leq$ $\min \left\{R_{2}(E, P), R_{2}(E, E)\right\}=R_{2}(E, P)$.

And from Lemmas 1,2:

4. $r_{P}^{*} \leq \widehat{r}_{c}(C, P)=\widehat{r}_{c}(C, E)$ for $r_{C}^{*}-r_{P}^{*}<\min \left\{R_{1}(C, P), R_{1}(C, E)\right\}=R_{1}(C, P)$

5. $r_{P}^{*}<\widehat{r}_{c}(C, P)<\widehat{r}_{p}(C, E)$ for $R_{1}(C, P)<r_{C}^{*}-r_{P}^{*} \leq R_{1}(C, E)$

6. $r_{P}^{*}<\widehat{r}_{p}(C, P)<\widehat{r}_{p}(C, E)$ for $R_{1}(C, E)<r_{C}^{*}-r_{P}^{*} \leq \min \left\{R_{2}(C, P), R_{2}(C, E)\right\}=$ $R_{2}(C, P)$

This proves part $b$ of the proposition. $\square$ 


\section{A.4 Proof of Proposition 4:}

a. Note first that under breakup it is materially optimal to set $r_{C}=r_{C}^{*}$ and $r_{P}=r_{P}^{*}$. Thus:

$$
\max _{r_{C}, r_{P}} V_{E}\left(r_{C}, r_{P}, 1\right)=-\triangle
$$

Under unification, $V_{E}\left(r_{C}, r_{P}, 0\right)=V_{E}(\widetilde{r}, \widetilde{r}, 0)=-\lambda\left(\widetilde{r}-r_{C}^{*}\right)^{2}-(1-\lambda)\left(\widetilde{r}-r_{P}^{*}\right)^{2}$. This is maximized when the common policy is set to $\widetilde{r}=\lambda r_{C}^{*}+(1-\lambda) r_{P}^{*}$. Thus:

$$
\max _{r_{C}, r_{P}} V_{E}\left(r_{C}, r_{P}, 0\right)=-\lambda(1-\lambda)\left(r_{C}^{*}-r_{P}^{*}\right)^{2}
$$

From equations (11), (12) and Definition 4, a materially optimal union will be sustained if and only if $r_{C}^{*}-r_{P}^{*} \leq \frac{\sqrt{\triangle}}{\sqrt{\lambda(1-\lambda)}}$. But from Lemmas 1 and $3, R_{2}(C, P)=R_{2}(E, P)=2 \sqrt{\triangle}<$ $\frac{\sqrt{\triangle}}{\sqrt{\lambda(1-\lambda)}}($ since $\lambda \in(0.5,1))$. This proves part $a$ of the proposition.

$b$. When the Periphery identifies with Europe, then for any given Core identity $I D_{C}$ there exist $\lambda \in(0.5,1)$ and $\gamma>0$ such that $R_{2}\left(I D_{C}, E\right)$ may be larger, smaller or equal to $\frac{\sqrt{\triangle}}{\sqrt{\lambda(1-\lambda)}} \cdot{ }^{10}$

Finally, we show that if $\lambda$ is sufficiently small then $R_{2}\left(I D_{C}, E\right)>\frac{\sqrt{\triangle}}{\sqrt{\lambda(1-\lambda)}}$ for any given Core identity $I D_{C}$. First, note that for a fixed $\triangle>0$ and $\gamma>0$ we have:

$$
\begin{array}{r}
\lim _{\lambda \rightarrow 0.5}\left(R_{2}(C, E)-\frac{\sqrt{\triangle}}{\sqrt{\lambda(1-\lambda)}}\right)=\lim _{\lambda \rightarrow 0.5}\left(\sqrt{\triangle}+\sqrt{\frac{(1+\gamma) \triangle}{1+\gamma-\gamma \lambda}}-\frac{\sqrt{\triangle}}{\sqrt{\lambda(1-\lambda)}}\right) \\
=\sqrt{\triangle}\left(\sqrt{\frac{(1+\gamma)}{1+\gamma / 2}}-1\right)>0 .
\end{array}
$$

Thus, for sufficiently small $\lambda, R_{2}(C, E)>\frac{\sqrt{\triangle}}{\sqrt{\lambda(1-\lambda)}}$.

To see that $R_{2}(E, E)>\frac{\sqrt{\triangle}}{\sqrt{\lambda(1-\lambda)}}$ for small $\lambda$, recall from Lemma 4 :

\footnotetext{
${ }^{10}$ For example, applying Lemmas 2 and $4, R_{2}(C, E)>\frac{\sqrt{\triangle}}{\sqrt{\lambda(1-\lambda)}}$ if $(\lambda, \gamma)=(0.55,0.1) ; R_{2}(C, E)<\frac{\sqrt{\Delta}}{\sqrt{\lambda(1-\lambda)}}$ if $(\lambda, \gamma)=(0.8,0.2) ; R_{2}(E, E)>\frac{\sqrt{\triangle}}{\sqrt{\lambda(1-\lambda)}}$ if $(\lambda, \gamma)=(0.65,0.7) ; R_{2}(E, E)<\frac{\sqrt{\triangle}}{\sqrt{\lambda(1-\lambda)}}$ if $(\lambda, \gamma)=(0.9,0.8)$.
} 
$R_{2}(E, E)= \begin{cases}\sqrt{\frac{(1+\gamma) \triangle}{(1+\gamma-\gamma \lambda)}}+\sqrt{\frac{(1+\gamma) \triangle}{(1+\gamma-\gamma \lambda)(1+\gamma \lambda)}} & \text { if } \gamma(1-\lambda) \leq \sqrt{1+\gamma \lambda} \\ \sqrt{\frac{(1+\gamma)^{2} \triangle}{\gamma(1-\lambda)(1+\gamma \lambda)}}, & \text { if } \gamma(1-\lambda)>\sqrt{1+\gamma \lambda}\end{cases}$

Note that $\lim _{\lambda \rightarrow 0.5} \sqrt{\frac{(1+\gamma)^{2} \triangle}{\gamma(1-\lambda)(1+\gamma \lambda)}}=\frac{(1+\gamma) \sqrt{\triangle}}{\sqrt{\frac{\gamma}{2}\left(1+\frac{\gamma}{2}\right)}}>2 \sqrt{\triangle}=\lim _{\lambda \rightarrow 0.5} \frac{\sqrt{\triangle}}{\sqrt{\lambda(1-\lambda)}}$ for every $\gamma>0$.

For the region $\gamma(1-\lambda) \leq \sqrt{1+\gamma \lambda}$, it is sufficient to show that $\sqrt{\triangle}\left(\sqrt{\frac{1+\gamma}{1+\frac{\gamma}{2}}}+\sqrt{\frac{1+\gamma}{\left(1+\frac{\gamma}{2}\right)^{2}}}\right)>$ $2 \sqrt{\triangle}$ if $\frac{\gamma}{2} \leq \sqrt{1+\frac{\gamma}{2}}$. But in this region of $\gamma, \sqrt{\triangle}\left(\sqrt{\frac{1+\gamma}{1+\frac{\gamma}{2}}}+\sqrt{\frac{1+\gamma}{\left(1+\frac{\gamma}{2}\right)^{2}}}\right) \geq \sqrt{\triangle}\left(\frac{\sqrt{1+\gamma}}{\frac{\gamma}{2}}+\frac{\sqrt{1+\gamma}}{\left(\frac{\gamma}{2}\right)^{2}}\right)=$ $\sqrt{\triangle} \frac{\sqrt{1+\gamma}}{\frac{\gamma}{2}}\left(1+\frac{2}{\gamma}\right)>2 \sqrt{\triangle}$.

\section{A.5 Ex-post Status Gaps}

The ex-post status of the Periphery $\left(S_{P}\right)$ and the Core $\left(S_{C}\right)$ are endogenously determined in SPNE. This section details the ex-post status gap for any given identity profile. This will be used for deriving the results in Section 5 .

Define $S G_{\left(I D_{C}, I D_{P}\right)}\left(r_{C}^{*}-r_{P}^{*}\right)$ as the ex-post status gap between the Core and the Periphery, i.e. $S_{C}-S_{P}$, in SPNE given identity profile $\left(I D_{C}, I D_{P}\right)$ when the level of fundamental differences between the countries is $r_{C}^{*}-r_{P}^{*}$.

Case $1(C, P)$ : Both Core and Periphery identify with their own country

The ex-post status gap can be derived directly from equation (3) and Lemma 1:

$$
S G_{(C, P)}\left(r_{C}^{*}-r_{P}^{*}\right)=\left\{\begin{array}{ccc}
\sigma_{C}-\sigma_{P}+\left(r_{C}^{*}-r_{P}^{*}\right)^{2} & \text { if } & r_{C}^{*}-r_{P}^{*} \leq R_{1}(C, P) \\
\sigma_{C}-\sigma_{P}-\left(r_{C}^{*}-r_{P}^{*}\right)^{2}+2 \sqrt{\triangle}\left(r_{C}^{*}-r_{P}^{*}\right) & \text { if } & R_{1}(C, P)<r_{C}^{*}-r_{P}^{*} \leq R_{2}(C, P) \\
\sigma_{C}-\sigma_{P} & \text { if } & r_{C}^{*}-r_{P}^{*}>R_{2}(C, P)
\end{array}\right.
$$

Case $2(C, E)$ : Core Identifies with own Country and Periphery identifies with Europe

Equation (3) and Lemma 2 imply:

$S G_{(C, E)}\left(r_{C}^{*}-r_{P}^{*}\right)=\left\{\begin{array}{ccc}\sigma_{C}-\sigma_{P}+\left(r_{C}^{*}-r_{P}^{*}\right)^{2} & \text { if } & r_{C}^{*}-r_{P}^{*} \leq R_{1}(C, E) \\ \sigma_{C}-\sigma_{P}-\left(r_{C}^{*}-r_{P}^{*}\right)^{2}+2 \sqrt{\frac{(1+\gamma) \triangle}{1+\gamma-\gamma \lambda}}\left(r_{C}^{*}-r_{P}^{*}\right) & \text { if } & R_{1}(C, E)<r_{C}^{*}-r_{P}^{*} \leq R_{2}(C, E) \\ \sigma_{C}-\sigma_{P} & \text { if } & r_{C}^{*}-r_{P}^{*}>R_{2}(C, E)\end{array}\right.$ 
Case $3(E, P)$ : Core Identifies with Europe and Periphery identifies with own country

Equation (3) and Lemma 3 imply:

$$
S G_{(E, P)}\left(r_{C}^{*}-r_{P}^{*}\right)=\left\{\begin{array}{ccc}
\sigma_{C}-\sigma_{P}+\frac{1-\gamma+2 \gamma \lambda}{1+\gamma}\left(r_{C}^{*}-r_{P}^{*}\right)^{2} & \text { if } & r_{C}^{*}-r_{P}^{*} \leq R_{1}(E, P) \\
\sigma_{C}-\sigma_{P}-\left(r_{C}^{*}-r_{P}^{*}\right)^{2}+2 \sqrt{\triangle}\left(r_{C}^{*}-r_{P}^{*}\right) & \text { if } & R_{1}(E, P)<r_{C}^{*}-r_{P}^{*} \leq R_{2}(E, P) \\
\sigma_{C}-\sigma_{P} & \text { if } & r_{C}^{*}-r_{P}^{*}>R_{2}(E, P)
\end{array}\right.
$$

Case $4(E, E)$ : Both Core and Periphery identify with Europe

Finally, equation (3) and Lemma 4 imply:

$$
S G_{(E, E)}\left(r_{C}^{*}-r_{P}^{*}\right)=\left\{\begin{array}{ccc}
\sigma_{C}-\sigma_{P}+\frac{1-\gamma+2 \gamma \lambda}{1+\gamma}\left(r_{C}^{*}-r_{P}^{*}\right)^{2} & \text { if } & r_{C}^{*}-r_{P}^{*} \leq R_{1}(E, E) \\
\sigma_{C}-\sigma_{P}-\left(r_{C}^{*}-r_{P}^{*}\right)^{2}+2 \sqrt{\frac{(1+\gamma) \triangle}{(1+\gamma-\gamma \lambda)}}\left(r_{C}^{*}-r_{P}^{*}\right) & \text { if } & R_{1}(E, E)<r_{C}^{*}-r_{P}^{*} \leq R_{2}(E, E) \\
\sigma_{C}-\sigma_{P} & \text { if } & r_{C}^{*}-r_{P}^{*}>R_{2}(E, E)
\end{array}\right.
$$

\section{A.6 Proof of Proposition 5:}

Assume $\sigma_{C}=\sigma_{P}=\sigma_{E}$.

a. The Core identifies nationally if $U_{C C}>U_{C E}$ or, using equation (9), if $S_{C}-S_{P}>0$. The Core identifies with Europe if $S_{C}-S_{P}<0$. Similarly, from equation (10), the Periphery identifies nationally if $S_{C}-S_{P}<0$ and with Europe if $S_{C}-S_{P}>0$. When $S_{C}-S_{P}=0$, both are indifferent between identifying nationally and identifying with Europe.

Given these choices of social identities, by Definition 5, an SIE in which the social identity profile is $(C, E)$ exists if and only if $S G_{(C, E)}\left(r_{C}^{*}-r_{P}^{*}\right) \geq 0 .{ }^{11}$ But under $\sigma_{C}=\sigma_{P}=\sigma_{E}$, it turns out that $S G_{(C, E)}\left(r_{C}^{*}-r_{P}^{*}\right) \geq 0$ for any level of fundamental differences $r_{C}^{*}-r_{P}^{*}$. To see this, notice that from equation (14) and Lemma 2:

- $S G_{(C, E)}\left(r_{C}^{*}-r_{P}^{*}\right)=0$ when $r_{C}^{*}-r_{P}^{*}=0$ and when $r_{C}^{*}-r_{P}^{*}>R_{2}(C, E)$;

- $S G_{(C, E)}\left(r_{C}^{*}-r_{P}^{*}\right)$ is increasing for $r_{C}^{*}-r_{P}^{*} \leq R_{1}(C, E)$;

- $S G_{(C, E)}\left(r_{C}^{*}-r_{P}^{*}\right)$ is decreasing for $R_{1}(C, E)<r_{C}^{*}-r_{P}^{*} \leq R_{2}(C, E)$;

- $S G_{(C, E)}\left(R_{2}(C, E)\right)>0$.

\footnotetext{
${ }^{11}$ See section A.5 for the definition of the function $S G_{\left(I D_{C}, I D_{P}\right)}\left(r_{C}^{*}-r_{P}^{*}\right)$.
} 
We conclude that an SIE exists for any level of fundamental differences between the countries. $b$. Suppose the union is sustained in SIE. From the proof of part $a$ we know that the $(C, E)$ profile is sustained in SIE under any level of $r_{C}^{*}-r_{P}^{*}$. And from Lemma 2, under the $(C, E)$ profile unification takes place when $r_{C}^{*}-r_{P}^{*} \leq R_{2}(C, E)$.

Consider now other identity profiles $\left(I D_{C}, I D_{P}\right) \neq(C, E)$ under the assumed ex-ante status restrictions. From equation (16), $S G_{(E, E)}\left(r_{C}^{*}-r_{P}^{*}\right)>0$ when $0<r_{C}^{*}-r_{P}^{*} \leq R_{2}(E, E)$. Since the Core identifies with Europe only if $S_{C}-S_{P} \leq 0$, the social identity profile $(E, E)$ cannot hold in SIE when fundamental differences are such that $0<r_{C}^{*}-r_{P}^{*} \leq R_{2}(E, E)$. Similarly, from equations (13) and (15), $S G_{\left(I D_{C}, P\right)}\left(r_{C}^{*}-r_{P}^{*}\right)>0$ when $0<r_{C}^{*}-r_{P}^{*}<R_{2}\left(I D_{C}, P\right)$. Since the Periphery identifies nationally only if $S_{C}-S_{P} \leq 0$, any social identity profile $\left(I D_{C}, P\right)$ cannot hold in SIE when $0<r_{C}^{*}-r_{P}^{*}<R_{2}\left(I D_{C}, P\right)$. Finally, since unification can only be sustained under profile $\left(I D_{C}, I D_{P}\right)$ when $r_{C}^{*}-r_{P}^{*} \leq R_{2}\left(I D_{C}, I D_{P}\right)$, we conclude that in almost any SIE in which the union is sustained, the social identity profile is $(C, E)$. There are two exceptions:

1. When $r_{C}^{*}-r_{P}^{*}=0$. From Proposition 1 we know that unification takes place in SPNE under any identity profile. And from equations (13)-(16) it is clear that under the assumed ex-ante status restrictions $S G_{\left(I D_{C}, I D_{P}\right)}(0)=0$ for all $\left(I D_{C}, I D_{P}\right)$. Hence, all social identity profiles can hold in SIE with unification.

2. When $r_{C}^{*}-r_{P}^{*}=R_{2}\left(I D_{C}, P\right)$. In this case both the $(C, P)$ and $(E, P)$ profiles can hold in an SIE with unification.

c. From the proof of Proposition 2, $R_{2}(C, E)>R_{2}(C, P)$. Thus, from the proof of part $b$ above, when $r_{C}^{*}-r_{P}^{*} \leq R_{2}(C, P)$, SIE implies unification.

Next, note that for any identity profile $\left(I D_{C}, I D_{P}\right)$, if $r_{C}^{*}-r_{P}^{*}>R_{2}\left(I D_{C}, I D_{P}\right)$ then equations (13)-(16) imply $S G_{\left(I D_{C}, I D_{P}\right)}\left(r_{C}^{*}-r_{P}^{*}\right)=0$. Hence, there exists an SIE in which breakup occurs and the social identity profile is $\left(I D_{C}, I D_{P}\right)$. Moreover, for fundamental differences such that $R_{2}(C, P)=R_{2}(E, P) \leq r_{C}^{*}-r_{P}^{*} \leq R_{2}(C, E)$, multiple SIE's exist, with and without unification.

$d$. This statement follows directly from the discussion of the $(E, E)$ case in part $b$ above and from the discussion of the case $r_{C}^{*}-r_{P}^{*}>R_{2}\left(I D_{C}, I D_{P}\right)$ in part $c$ above. 


\section{A.7 Proof of Proposition 6:}

Assume $\sigma_{C}>\sigma_{E}>\sigma_{P}$. Thus, $\frac{\sigma_{E}-\sigma_{C}}{1-\lambda}, \frac{\sigma_{P}-\sigma_{E}}{\lambda}<0$. From Equation (14) and Lemma 2 it then follows that

$$
S G_{(C, E)}\left(r_{C}^{*}-r_{P}^{*}\right)>\max \left\{\sigma_{C}-\sigma_{P}+\frac{\sigma_{E}-\sigma_{C}}{1-\lambda}, \sigma_{C}-\sigma_{P}+\frac{\sigma_{P}-\sigma_{E}}{\lambda}\right\}
$$

for any level of fundamental differences $r_{C}^{*}-r_{P}^{*}$. But from Definition 5 and equations (9) and (10), this implies that an SIE in which the social identity profile is $(C, E)$ exists for any level of fundamental differences between the countries.

Furthermore, from equations (13), (15) and (16) it follows that for every social identity profile $\left(I D_{C}, I D_{P}\right) \neq(C, E)$, we have that

$$
S G_{\left(I D_{C}, I D_{P}\right)}\left(r_{C}^{*}-r_{P}^{*}\right)>\max \left\{\sigma_{C}-\sigma_{P}+\frac{\sigma_{E}-\sigma_{C}}{1-\lambda}, \sigma_{C}-\sigma_{P}+\frac{\sigma_{P}-\sigma_{E}}{\lambda}\right\}
$$

for every $r_{C}^{*}-r_{P}^{*}$. Hence, either the Core would not identify with $I D_{C}$ or the Periphery would not identify with $I D_{P}$ in the SPNE given $\left(I D_{C}, I D_{P}\right)$. Thus, no social identity profile $\left(I D_{C}, I D_{P}\right) \neq(C, E)$ can hold in SIE. It follows that for every $r_{C}^{*}-r_{P}^{*}$ there exists a unique SIE in which the identity profile has the Core identifying nationally and the Periphery identifying with Europe. From Lemma 2 we know that unification occurs in this SIE if and only if $r_{C}^{*}-r_{P}^{*} \leq R_{2}(C, E)$.

\section{A.8 Proof of Proposition 7:}

Assume $\sigma_{P}>\sigma_{E}>\sigma_{C}$. Furthermore, we provide here the proof for the case in which $\sigma_{E}>\lambda \sigma_{C}+(1-\lambda) \sigma_{P}$, corresponding to Panel B in Figure 7. The proof is similar for the case $\sigma_{E} \leq \lambda \sigma_{C}+(1-\lambda) \sigma_{P}$.

a. Consider an SIE in which the social identity profile is $(E, P)$. From Definition 5 and equations (9) and (10), such an SIE exists if and only if

$S G_{(E, P)}\left(r_{C}^{*}-r_{P}^{*}\right) \leq \min \left\{\sigma_{C}-\sigma_{P}+\frac{\sigma_{E}-\sigma_{C}}{1-\lambda}, \sigma_{C}-\sigma_{P}+\frac{\sigma_{P}-\sigma_{E}}{\lambda}\right\}=\sigma_{C}-\sigma_{P}+\frac{\sigma_{P}-\sigma_{E}}{\lambda}$.

From equation (15), it immediately follows that condition (17) holds when $r_{C}^{*}-r_{P}^{*}=0$ and when $r_{C}^{*}-r_{P}^{*} \geq R_{2}(E, P)$.

Next, focus on the intermediate level of fundamental differences $r_{C}^{*}-r_{P}^{*} \in\left(0, R_{2}(E, P)\right)$. By contradiction, suppose that there exists some $r_{C}^{*}-r_{P}^{*}$ in this region such that there does not exist an SIE. Denote this level of $r_{C}^{*}-r_{P}^{*}$ by $\bar{r}$. Then, from condition (17) it 
follows that $S G_{(E, P)}(\bar{r})>\sigma_{C}-\sigma_{P}+\frac{\sigma_{P}-\sigma_{E}}{\lambda}$. In addition $S G_{(C, E)}(\bar{r})<\sigma_{C}-\sigma_{P}+\frac{\sigma_{E}-\sigma_{C}}{1-\lambda}$, since given Definition 5 and equations (9) and (10), an SIE in which the social identity profile is $(C, E)$ holds if and only if $S G_{(C, E)}\left(r_{C}^{*}-r_{P}^{*}\right) \geq \sigma_{C}-\sigma_{P}+\frac{\sigma_{E}-\sigma_{C}}{1-\lambda}$. Finally, note that $S G_{(E, P)}\left(r_{C}^{*}-r_{P}^{*}\right) \leq S G_{(E, E)}\left(r_{C}^{*}-r_{P}^{*}\right) \leq S G_{(C, E)}\left(r_{C}^{*}-r_{P}^{*}\right)$ for every $r_{C}^{*}-r_{P}^{*}$ (this can be algebraically verified from equations (14)-(16) and Lemmas 2-4). Thus, it must be the case that $\sigma_{C}-\sigma_{P}+\frac{\sigma_{P}-\sigma_{E}}{\lambda}<S G_{(E, E)}(\bar{r})<\sigma_{C}-\sigma_{P}+\frac{\sigma_{E}-\sigma_{C}}{1-\lambda}$. But by Definition 5 and equations (9) and (10), this means that an SIE in which the identity profile is $(E, E)$ exists when $r_{C}^{*}-r_{P}^{*}=\bar{r}$. We therefore conclude that an SIE exists for every level of $r_{C}^{*}-r_{P}^{*}$.

$b$. From part $a$ above we know that when $r_{C}^{*}-r_{P}^{*}>R_{2}(E, P)$ there exists an SIE with an $(E, P)$ social identity profile. From Lemma 3 we know that breakup occurs in this SIE. But from the proof of Proposition 2, $R_{2}(C, E)>R_{2}(C, P)=R_{2}(E, P)$. Thus, breakup can occur in SIE when $r_{C}^{*}-r_{P}^{*}<R_{2}(C, E)$.

c. From equations (13)-(16) it follows that for any $\left(I D_{C}, I D_{P}\right)$,

$S G_{\left(I D_{C}, I D_{P}\right)}\left(r_{C}^{*}-r_{P}^{*}\right)<\sigma_{C}-\sigma_{P}+\frac{\sigma_{P}-\sigma_{E}}{\lambda}=\min \left\{\sigma_{C}-\sigma_{P}+\frac{\sigma_{E}-\sigma_{C}}{1-\lambda}, \sigma_{C}-\sigma_{P}+\frac{\sigma_{P}-\sigma_{E}}{\lambda}\right\}$

whenever $r_{C}^{*}-r_{P}^{*} \geq R_{2}\left(I D_{C}, I D_{P}\right)$. Equations (9) and (10) then imply that for any $\left(I D_{C}, I D_{P}\right)$, whenever $r_{C}^{*}-r_{P}^{*} \geq R_{2}\left(I D_{C}, I D_{P}\right)$ in SIE the Core identifies with Europe while the Periphery identifies nationally. Thus, in any SIE in which breakup occurs, the social identity profile must be $(E, P)$.

$d$. From Proposition 1 and the proof of Proposition 2, we know that when $r_{C}^{*}-r_{P}^{*}<R_{2}(E, P)$ unification occurs in any $\mathrm{SIE}$ (since $R_{2}(E, P) \leq R_{2}\left(I D_{C}, I D_{P}\right)$ for every $\left(I D_{C}, I D_{P}\right)$ ). Similarly, when $r_{C}^{*}-r_{P}^{*} \geq R(C, E)$ breakup occurs in any SIE $\left(\right.$ since $R_{2}(C, E)>R_{2}\left(I D_{C}, I D_{P}\right)$ for every $\left.\left(I D_{C}, I D_{P}\right)\right)$. Consider then the intermediate region of fundamental differences such that $R_{2}(E, P)<r_{C}^{*}-r_{P}^{*} \leq R_{2}(C, E)$.

From the proofs of parts $a$ and $c$ above, for every level of fundamental differences in this region there exists an SIE with an $(E, P)$ social identity profile in which breakup occurs. Furthermore, since $S G_{\left(I D_{C}, P\right)}\left(r_{C}^{*}-r_{P}^{*}\right)<\sigma_{C}-\sigma_{P}+\frac{\sigma_{P}-\sigma_{E}}{\lambda}$ throughout this region for every Core identity $I D_{c}$, it follows that in any SIE in this region in which the Periphery identifies nationally, breakup must occur. We are thus left to show that there exist levels of fundamental differences in this intermediate region for which an SIE with unification exists.

To see this, recall that an SIE in which the social identity profile is $(C, E)$ holds if and only if $S G_{(C, E)}\left(r_{C}^{*}-r_{P}^{*}\right) \geq \sigma_{C}-\sigma_{P}+\frac{\sigma_{E}-\sigma_{C}}{1-\lambda}$. Since $S G_{(C, E)}\left(r_{C}^{*}-r_{P}^{*}\right)$ is continuous at $R_{2}(E, P)$, if $S G_{(C, E)}\left(R_{2}(E, P)\right)>\sigma_{C}-\sigma_{P}+\frac{\sigma_{E}-\sigma_{C}}{1-\lambda}$ then there exist levels of $r_{C}^{*}-r_{P}^{*}$ throughout this intermediate range for which this SIE holds (i.e., there exists an $\epsilon>0$ such that for every $R_{2}(E, P) \leq r_{C}^{*}-r_{P}^{*}<R_{2}(E, P)+\epsilon$ we have that $\left.S G_{(C, E)}\left(r_{C}^{*}-r_{P}^{*}\right) \geq \sigma_{C}-\sigma_{P}+\frac{\sigma_{E}-\sigma_{C}}{1-\lambda}\right)$. 
From the proof of Proposition 2 we know that $R_{2}(E, P)<R_{2}(C, E)$ so unification occurs in this SIE. This proves part $d$.

$e$. The $(E, E)$ social identity profile is sustained in SIE if and only if:

$$
\sigma_{C}-\sigma_{P}+\frac{\sigma_{P}-\sigma_{E}}{\lambda} \leq S G_{(E, E)}\left(r_{C}^{*}-r_{P}^{*}\right) \leq \sigma_{C}-\sigma_{P}+\frac{\sigma_{E}-\sigma_{C}}{1-\lambda} .
$$

First, we note that since $S G_{(E, E)}\left(r_{C}^{*}-r_{P}^{*}\right)<\sigma_{C}-\sigma_{P}+\frac{\sigma_{P}-\sigma_{E}}{\lambda}$ when $r_{C}^{*}-r_{P}^{*}=0$ and when $r_{C}^{*}-r_{P}^{*}>R_{2}(E, E)$, this identity profile cannot be sustained in SIE throughout these levels of fundamental differences. However, if $S G_{(E, E)}\left(R_{1}(E, E)\right) \geq \sigma_{C}-\sigma_{P}+\frac{\sigma_{P}-\sigma_{E}}{\lambda}$ then there are levels of $r_{C}^{*}-r_{P}^{*} \in\left(0, R_{2}(E, E)\right]$ for which there exists an SIE with an $(E, E)$ identity profile (since $S G_{(E, E)}\left(r_{C}^{*}-r_{P}^{*}\right.$ ) is left-continuous at $r_{C}^{*}-r_{P}^{*}=R_{1}(E, E)$ ).

\section{B Integration when Policy is Flexible}

The model we have discussed throughout the paper is a sticky policy model. Having set the policy for the union, the Core cannot adjust it in case the Periphery chooses to leave the union. This is reasonable when the compound policy is complex and cannot be changed immediately (e.g. laws and regulations or immigration policies). However, some policies (e.g. interest rates) might be more easily adaptable in the short run.

In what follows we analyze the case in which the Core's policy is flexible in the sense that it is able to freely adjust it in case of breakup. As in the sticky policy model, the Core moves first and sets the policy instrument at some level $r_{C}=\hat{r}$. The Periphery then either accepts or rejects this policy. If it accepts then $r_{P}=r_{C}=\hat{r}$. If it rejects then both countries (rather than the Periphery alone) are free to set their own policies. Social identities still affect the policies set and the unification resolution in SPNE. Our main qualitative results continue to hold when policy is flexible. Specifically, the union is most robust, and least accommodating, under the $(C, E)$ social identity profile. The properties of SIE also follow a similar pattern.

\section{B.1 Integration given Social Identities}

It is again useful to begin with a general characterization of the Subgame Perfect Nash Equilibrium (SPNE) outcome under any given profile of identities. The following Proposition replicates Proposition 1 for the case of a flexible policy (see discussion and analysis of this result in Section 3). 
Proposition B.1. Subgame Perfect Equilibrium (SPNE). For any profile of social identities $\left(I D_{c}, I D_{p}\right)$ there exist cutoffs $\widetilde{R_{1}}=\widetilde{R_{1}}\left(I D_{c}, I D_{p}\right)$ and $\widetilde{R_{2}}=\widetilde{R_{2}}\left(I D_{c}, I D_{p}\right)$ and policies (functions of $r_{C}^{*}$ and $r_{P}^{*}$ ) $\widetilde{r_{C}}=\widetilde{r_{C}}\left(I D_{c}, I D_{p}\right)$ and $\widetilde{r_{P}}=\widetilde{r_{P}}\left(I D_{c}, I D_{p}\right)$ such that $\widetilde{R_{1}} \leq \widetilde{R_{2}}, \widetilde{r_{P}}<\widetilde{r_{C}}$ and:

a. If $r_{C}^{*}-r_{P}^{*} \leq \widetilde{R_{1}}$ then in SPNE unification occurs and $r_{C}=r_{P}=\widetilde{r_{C}}$.

b. If $\widetilde{R_{1}}<r_{C}^{*}-r_{P}^{*} \leq \widetilde{R_{2}}$ then in SPNE unification occurs and $r_{C}=r_{P}=\widetilde{r_{P}}$.

c. If $r_{C}^{*}-r_{P}^{*}>\widetilde{R_{2}}$ then in SPNE breakup occurs and $r_{C}=r_{C}^{*}, r_{P}=r_{P}^{*}$.

Proof. Taking the social identities as given, we solve the sequential bargaining game for each of the social identity profiles when the policy is flexible. From Lemmas B.1-B.4 we will then obtain Proposition B.1.

Case $1(C, P)$ : Both Core and Periphery identify with their own country.

Lemma B.1.

a. $\widetilde{R_{1}}(C, P)=\sqrt{\triangle}, \widetilde{R_{2}}(C, P)=2 \sqrt{\triangle}$

b. $\widetilde{r_{C}}(C, P)=r_{C}^{*}, \widetilde{r_{P}}(C, P)=r_{P}^{*}+\sqrt{\triangle}$

Proof. Given the $(C, P)$ social identity profile, the solution is identical to the sticky policy case. When the Periphery identifies nationally, it accepts $r_{C}$ to the same extent of fundamental differences between the countries, regardless of whether or not the Core is able to adjust its policy in the case of breakup (see proof of Proposition 1). When the Periphery is concerned only with its own material payoff, it does not care whether or not the Core is able to adjust its policy. This in turn leads the Core to set its policy exactly as it did when the policy was sticky. The proof is thus identical to the proof of Lemma 1.

Case $2(C, E)$ : Core Identifies with own Country and Periphery identifies with Europe

\section{Lemma B.2.}

a. $\widetilde{R_{1}}(C, E)=\sqrt{\frac{(1+\gamma) \triangle}{1+\gamma-\gamma \lambda}}$

$$
\widetilde{R_{2}}(C, E)=\left\{\begin{array}{cll}
\sqrt{\frac{1+\gamma}{\gamma \lambda} \sqrt{\frac{(1+\gamma) \triangle}{1+\gamma-\gamma \lambda}}} & \text { if } & 1+\gamma-2 \gamma \lambda<0 \\
\frac{(1+\gamma) \sqrt{\triangle}}{1+\gamma-\gamma \lambda} & \text { if } & 1+\gamma-2 \gamma \lambda=0 \\
2 \sqrt{\triangle} & \text { if } & 1+\gamma-2 \gamma \lambda>0
\end{array}\right.
$$


b. $\widetilde{r_{C}}(C, E)=r_{C}^{*}, \widetilde{r_{P}}(C, E)=\frac{(1+\gamma-\gamma \lambda) r_{P}^{*}+\gamma \lambda r_{C}^{*}+\sqrt{(1+\gamma)^{2} \triangle-\gamma \lambda(1+\gamma-\gamma \lambda)\left(r_{C}^{*}-r_{P}^{*}\right)^{2}}}{1+\gamma}$

Proof. Recall that Core utility is given by equation (5) and that Periphery utility is given by equation (7).

When the Periphery identifies with Europe, utility depends on whether it accepts $r_{C}$ or not (in which case it sets $r_{P}$ to $r_{P}^{*}$ ). Clearly, whenever breakup occurs in the flexible policy model (i.e. the Periphery rejects $r_{C}$ ) the Core will set its policy to $r_{C}^{*}$ in order to maximize own material payoffs. Thus, Periphery utility is:

$$
U_{P E}=\left\{\begin{array}{ccc}
-(1+\gamma-\gamma \lambda)\left(r_{C}-r_{P}^{*}\right)^{2}-\gamma \lambda\left(r_{C}-r_{C}^{*}\right)^{2}+\gamma \sigma_{E} & \text { if } & \text { Accepts } \\
-(1+\gamma) \triangle+\gamma \sigma_{E} & \text { if } & \text { Rejects }
\end{array}\right.
$$

Solving the game by backward induction, the Periphery is willing to accept $r_{C}$ if and only if $\left.U_{P E}\right|_{\text {accepts }} \geq\left. U_{P E}\right|_{\text {rejects. }}$. First note that when fundamental differences are such that $r_{C}^{*}-r_{P}^{*}>\sqrt{\frac{1+\gamma}{\gamma \lambda}} \sqrt{\frac{(1+\gamma) \triangle}{1+\gamma-\gamma \lambda}}$, we have that $\left.U_{P E}\right|_{\text {accepts }}<\left.U_{P E}\right|_{\text {rejects }}$ for every $r_{C}$. Thus, breakup will occur throughout this range of fundamental differences, regardless of the policy set by the Core. Because the Periphery is aware of the Core being able to set its policy to $r_{C}^{*}$ in case of breakup, and because it cares about the Core's material payoffs, breakup will occur when differences between the countries are sufficiently large.

When the Core identifies nationally, its chosen policy when there is no threat of secession is $r_{C}^{*}$, which we denote by $\widetilde{r_{C}}(C, E)$. Note that when $r_{C}^{*}-r_{P}^{*} \leq \sqrt{\frac{(1+\gamma) \triangle}{1+\gamma-\gamma \lambda}}$ the Core is indeed able to set its policy to $r_{C}^{*}$ without suffering the cost of breakup (given $r_{C}=r_{C}^{*}$, $\left.U_{P E}\right|_{\text {accepts }} \geq\left. U_{P E}\right|_{\text {rejects }}$ if and only if $\left.r_{C}^{*}-r_{P}^{*} \leq \sqrt{\frac{(1+\gamma) \triangle}{1+\gamma-\gamma \lambda}}\right)$. We denote this cutoff by $\widetilde{R_{1}}(C, E)$.

When $\widetilde{R_{1}}(C, E)<r_{C}^{*}-r_{P}^{*} \leq \sqrt{\frac{1+\gamma}{\gamma \lambda}} \sqrt{\frac{(1+\gamma) \triangle}{1+\gamma-\gamma \lambda}}$, the Core decides between the following two options:

1. Set the policy that maximizes utility under breakup, which is $r_{C}^{*}$. Utility will then be:

$$
\left.U_{C C}\right|_{\text {breakup }}=-(1+\gamma) \triangle+\gamma \sigma_{C}
$$

2. Set the policy that maximizes utility under the constraint that the union is sustained (i.e choose among the policies that would be accepted by the Periphery). This policy, which we denote by $\widetilde{r_{P}}(C, E)$, solves the following maximization problem:

$$
\operatorname{Max}_{r_{C}}-(1+\gamma)\left(r_{C}-r_{C}^{*}\right)^{2}+\gamma \sigma_{C} \text { s.t }\left.\quad U_{P E}\right|_{\text {accepts }} \geq\left. U_{P E}\right|_{\text {rejects }}
$$


The solution is:

$$
\widetilde{r_{P}}(C, E)=\frac{(1+\gamma-\gamma \lambda) r_{P}^{*}+\gamma \lambda r_{C}^{*}+\sqrt{(1+\gamma)^{2} \triangle-\gamma \lambda(1+\gamma-\gamma \lambda)\left(r_{C}^{*}-r_{P}^{*}\right)^{2}}}{1+\gamma} .
$$

Utility will then be:

$$
\left.U_{C C}\right|_{\text {unification }}-\frac{\left[(1+\gamma-\gamma \lambda)\left(r_{P}^{*}-r_{C}^{*}\right)+\sqrt{(1+\gamma)^{2} \triangle-\gamma \lambda(1+\gamma-\gamma \lambda)\left(r_{C}^{*}-r_{P}^{*}\right)^{2}}\right]^{2}}{1+\gamma}+\gamma \sigma_{C} .
$$

In SPNE the Core sets the policy to $\widetilde{r_{P}}(C, E)$ if and only if $\left.U_{C C}\right|_{\text {unification }} \geq\left. U_{C C}\right|_{\text {breakup }}$. This condition is satisfied when one of the following holds:

1. $r_{C}^{*}-r_{P}^{*} \leq \frac{(1+\gamma) \sqrt{\triangle}}{1+\gamma-\gamma \lambda}$

2. $r_{C}^{*}-r_{P}^{*}>\frac{(1+\gamma) \sqrt{\triangle}}{1+\gamma-\gamma \lambda}$ and $r_{C}^{*}-r_{P}^{*} \leq 2 \sqrt{\triangle}$

Recalling that breakup necessarily occurs whenever $r_{C}^{*}-r_{P}^{*}>\sqrt{\frac{1+\gamma}{\gamma \lambda}} \sqrt{\frac{(1+\gamma) \triangle}{1+\gamma-\gamma \lambda}}$ (see above), we have that the cutoff for breakup, which we denote by $\widetilde{R_{2}}(C, E)$, is:

$$
\widetilde{R_{2}}(C, E)=\left\{\begin{array}{cll}
\sqrt{\frac{1+\gamma}{\gamma \lambda} \sqrt{\frac{(1+\gamma) \triangle}{1+\gamma-\gamma \lambda}}} & \text { if } & 1+\gamma-2 \gamma \lambda<0 \\
\frac{(1+\gamma) \sqrt{\triangle}}{1+\gamma-\gamma \lambda} & \text { if } & 1+\gamma-2 \gamma \lambda=0 . \\
2 \sqrt{\triangle} & \text { if } & 1+\gamma-2 \gamma \lambda>0
\end{array}\right.
$$

In summary, the SPNE in the flexible model for the $(C, E)$ social identity profile is:

1. If $r_{C}^{*}-r_{P}^{*} \leq \widetilde{R_{1}}(C, E)$ then unification occurs and $r_{C}=r_{P}=\widetilde{r_{C}}(C, E)$.

2. If $\widetilde{R_{1}}(C, E)<r_{C}^{*}-r_{P}^{*} \leq \widetilde{R_{2}}(C, E)$ then unification occurs and $r_{C}=r_{P}=\widetilde{r_{P}}(C, E)$.

3. If $r_{C}^{*}-r_{P}^{*}>\widetilde{R_{2}}(C, E)$ then breakup occurs and $r_{C}=r_{C}^{*}, r_{C}=r_{P}^{*}$.

When the Periphery cares about the Core's material payoffs its reserve utility (i.e. the utility gained in case of breakup) is higher relative to the sticky model case. When the Core can respond to breakup by adjusting its policy to $r_{C}^{*}$, breakup is less costly from a material payoff perspective. Thus, the Periphery's utility from breakup is higher when the policy is flexible. As a result the concessions the Core has to make in the intermediate range of fundamental differences in order to keep the Periphery in the union are larger (i.e. $\widetilde{r_{P}}(C, E)<r_{P}(C, E)$ ) and the union is less robust (i.e. $\widetilde{R_{2}}(C, E)<R_{2}(C, E)$ ). 
Case $3(E, P)$ : Core identifies with Europe and Periphery identifies with own Country

\section{Lemma B.3.}

a. $\widetilde{R_{1}}(E, P)=\frac{1+\gamma}{1+\gamma \lambda} \sqrt{\triangle}, \widetilde{R_{2}}(E, P)=2 \sqrt{\triangle}$

b. $\widetilde{r_{C}}(E, P)=\frac{(1+\gamma \lambda) r_{C}^{*}+\gamma(1-\lambda) r_{P}^{*}}{1+\gamma}, \widetilde{r_{P}}(E, P)=r_{P}^{*}+\sqrt{\triangle}$

Proof. As in the $(C, P)$ case, when the Periphery identifies nationally the SPNE in the flexible model is identical to the SPNE in the sticky model. The proof is thus identical to the proof of Lemma 3 .

Case $4(E, E)$ : Both Core and Periphery identify with Europe

\section{Lemma B.4.}

a. $\widetilde{R_{1}}(E, E)=\sqrt{\frac{(1+\gamma)^{3} \triangle}{(1+\gamma-\gamma \lambda)(1+\gamma \lambda)^{2}+\gamma^{3} \lambda(1-\lambda)^{2}}}$

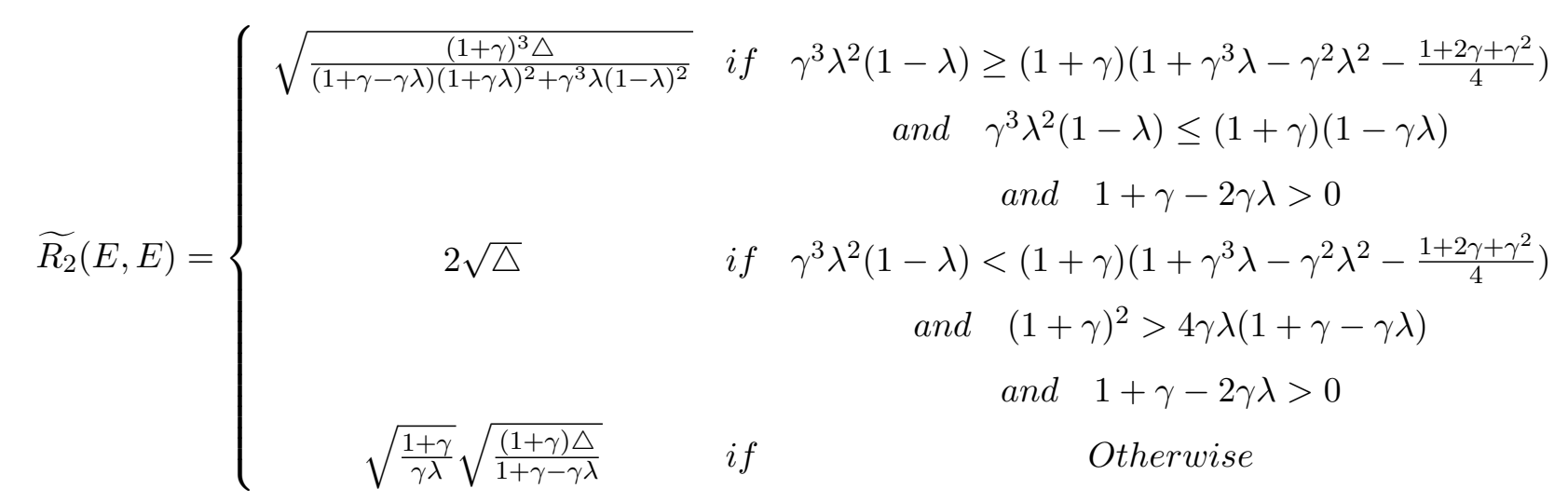

b. $\widetilde{r_{C}}(E, E)=\frac{(1+\gamma \lambda) r_{C}^{*}+\gamma(1-\lambda) r_{P}^{*}}{1+\gamma}$

$$
\widetilde{r_{P}}(C, E)=\frac{(1+\gamma-\gamma \lambda) r_{P}^{*}+\gamma \lambda r_{C}^{*}+\sqrt{(1+\gamma)^{2} \triangle-\gamma \lambda(1+\gamma-\gamma \lambda)\left(r_{C}^{*}-r_{P}^{*}\right)^{2}}}{1+\gamma}
$$

Proof. Core utility is again given by equation (8). As in the $(C, E)$ case, Periphery utility is given by equation (18).

The Periphery is willing to accept $r_{C}$ if and only if $\left.U_{P E}\right|_{\text {accepts }} \geq\left. U_{P E}\right|_{\text {rejects }}$. First note that, as in the $(C, E)$ case, when fundamental differences are such that $r_{C}^{*}-r_{P}^{*}>$ $\sqrt{\frac{1+\gamma}{\gamma \lambda}} \sqrt{\frac{(1+\gamma) \triangle}{1+\gamma-\gamma \lambda}}$ we have that $\left.U_{P E}\right|_{\text {accepts }}<\left.U_{P E}\right|_{\text {rejects }}$ for every $r_{C}$. Thus, breakup will occur throughout this range of fundamental differences, regardless of the policy set by the Core.

When the Core identifies with Europe, its chosen policy when there is no threat of secession is $\frac{(1+\gamma \lambda) r_{C}^{*}+\gamma(1-\lambda) r_{P}^{*}}{1+\gamma}$ (see proof of Lemmas 3 and 4 ). We denote this policy by 
$\widetilde{r_{C}}(E, E)$. Note that when $r_{C}^{*}-r_{P}^{*} \leq \sqrt{\frac{(1+\gamma)^{3} \Delta}{(1+\gamma-\gamma \lambda)(1+\gamma \lambda)^{2}+\gamma^{3} \lambda(1-\lambda)^{2}}}$ the Core is indeed able to set its policy to $\widetilde{r_{C}}(E, E)$ without suffering the cost of breakup (given $r_{C}=\widetilde{r_{C}}(E, E)$, $\left.U_{P E}\right|_{\text {accepts }} \geq\left. U_{P E}\right|_{\text {rejects }}$ if and only if $\left.r_{C}^{*}-r_{P}^{*} \leq \sqrt{\frac{(1+\gamma)^{3} \Delta}{(1+\gamma-\gamma \lambda)(1+\gamma \lambda)^{2}+\gamma^{3} \lambda(1-\lambda)^{2}}}\right)$. We denote this cutoff by $\widetilde{R_{1}}(E, E)$.

When $\widetilde{R_{1}}(E, E)<r_{C}^{*}-r_{P}^{*} \leq \sqrt{\frac{1+\gamma}{\gamma \lambda}} \sqrt{\frac{(1+\gamma) \triangle}{1+\gamma-\gamma \lambda}}$ the Core decides between the following two options:

1. Set the policy that maximizes utility under breakup, which is $r_{C}^{*}$. In this case utility is:

$$
\left.U_{C E}\right|_{\text {breakup }}=-(1+\gamma) \triangle+\gamma \sigma_{E}
$$

2. Set the policy that maximizes utility under the constraint that the union is sustained (i.e choose among the policies that would be accepted by the Periphery). This policy, which we denote by $\widetilde{r_{P}}(C, E)$, solves the following maximization problem:

$$
\operatorname{Max}_{r_{C}}-(1+\gamma \lambda)\left(r_{C}-r_{C}^{*}\right)^{2}-\gamma(1-\lambda)\left(r_{C}-r_{P}^{*}\right)^{2}+\gamma \sigma_{E} \quad \text { s.t }\left.\quad U_{P E}\right|_{\text {accepts }} \geq\left. U_{P E}\right|_{\text {rejects }} .
$$

The solution is:

$$
\widetilde{r_{P}}(E, E)=\frac{(1+\gamma-\gamma \lambda) r_{P}^{*}+\gamma \lambda r_{C}^{*}+\sqrt{(1+\gamma)^{2} \triangle-\gamma \lambda(1+\gamma-\gamma \lambda)\left(r_{C}^{*}-r_{P}^{*}\right)^{2}}}{1+\gamma} .
$$

Utility will then be:

$$
\begin{aligned}
\left.U_{C E}\right|_{\text {unification }} & =-(1+\gamma \lambda) \frac{\left[(1+\gamma-\gamma \lambda)\left(r_{P}^{*}-r_{C}^{*}\right)+\sqrt{(1+\gamma)^{2} \Delta-\gamma \lambda(1+\gamma-\gamma \lambda)\left(r_{C}^{*}-r_{P}^{*}\right)^{2}}\right]^{2}}{(1+\gamma)^{2}} \\
& -\gamma(1-\lambda) \frac{\left[\gamma \lambda\left(r_{C}^{*}-r_{P}^{*}\right)+\sqrt{(1+\gamma)^{2} \Delta-\gamma \lambda(1+\gamma-\gamma \lambda)\left(r_{C}^{*}-r_{P}^{*}\right)^{2}}\right]^{2}}{(1+\gamma)^{2}}+\gamma \sigma_{E} .
\end{aligned}
$$

In SPNE the Core sets the policy to $\widetilde{r_{P}}(E, E)$ if and only if $\left.U_{C E}\right|_{\text {unification }} \geq\left. U_{C E}\right|_{\text {breakup }}$. This condition is satisfied when one of the following holds:

1. $1+\gamma-2 \gamma \lambda \leq 0$

2. $1+\gamma-2 \gamma \lambda>0$ and $r_{C}^{*}-r_{P}^{*} \leq 2 \sqrt{\triangle}$

Recalling that breakup necessarily occurs whenever $r_{C}^{*}-r_{P}^{*}>\sqrt{\frac{1+\gamma}{\gamma \lambda}} \sqrt{\frac{(1+\gamma) \Delta}{1+\gamma-\gamma \lambda}}$ (see above), we have that the cutoff for breakup, which we denote by $\widetilde{R_{2}}(E, E)$, is: 


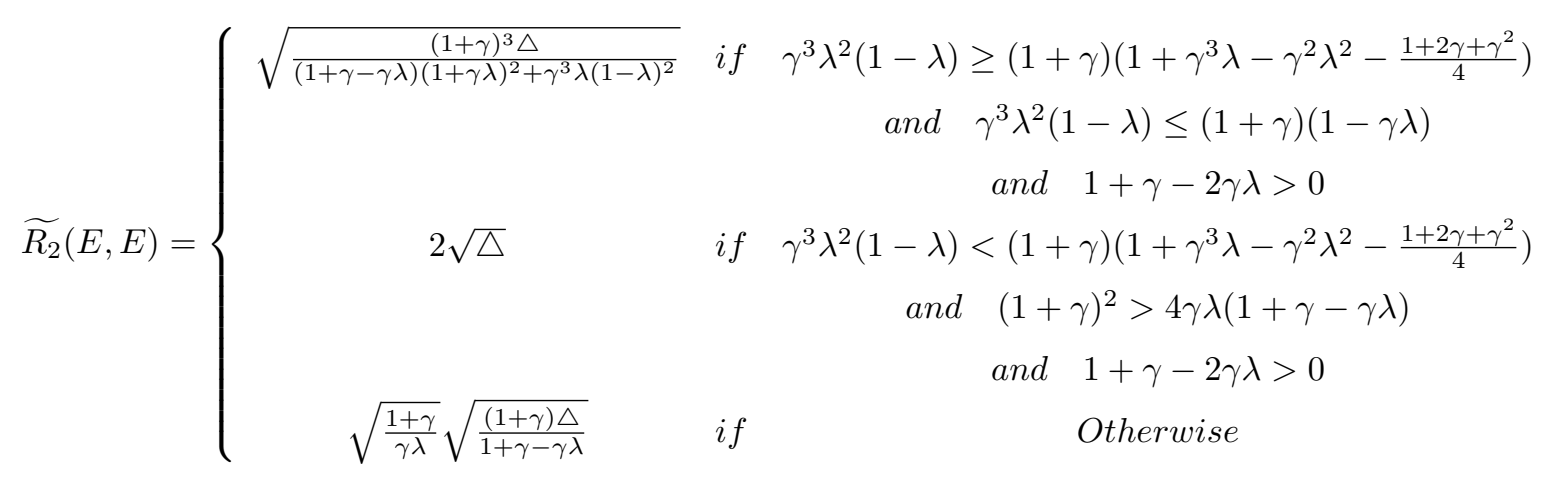

In summary, the SPNE in the flexible model for the $(E, E)$ social identity profile is:

1. If $r_{C}^{*}-r_{P}^{*} \leq \widetilde{R_{1}}(E, E)$ then unification occurs and $r_{C}=r_{P}=\widetilde{r_{C}}(E, E)$.

2. If $\widetilde{R_{1}}(E, E)<r_{C}^{*}-r_{P}^{*} \leq \widetilde{R_{2}}(E, E)$ then unification occurs and $r_{C}=r_{P}=\widetilde{r_{P}}(E, E)$.

3. If $r_{C}^{*}-r_{P}^{*}>\widetilde{R_{2}}(E, E)$ then breakup occurs and $r_{C}=r_{C}^{*}, r_{C}=r_{P}^{*}$.

\section{B.1.1 Robustness and Accommodation in the Flexible Model}

Our main results regarding the robustness of unions and the degree to which they accommodate the Periphery continue to hold when the policy is a flexible one. They are stated in Propositions B.2 and B.3. Proofs rely on simple algebra and follow the proofs of the equivalent Propositions 2 and 3 from the sticky policy model (See Appendix A).

\section{Proposition B.2. Robustness in the flexible model.}

a. The union is more robust when the Core identifies with the nation than when it identifies with Europe: $\widetilde{R_{2}}\left(C, I D_{P}\right) \geq \widetilde{R_{2}}\left(E, I D_{P}\right)$ for all $I D_{P} \in\{P, E\}$.

b. The union is strictly more robust when the Periphery identifies with Europe than when it identifies with the nation: $\widetilde{R_{2}}\left(I D_{C}, E\right) \geq \widetilde{R_{2}}\left(I D_{C}, P\right)$ for all I $D_{C} \in\{C, E\}$.

\section{Proposition B.3. Accommodation in the flexible model.}

a. For any given Periphery identity, the union is more accommodating if Core members identify with Europe rather than with their nation.

b. For any given Core identity, the union is more accommodating if members of the Periphery identify with their nation rather than with Europe.

As in the sticky policy model, an important corollary follows.

Corollary 2. The union is most robust and least accommodating under the $(C, E)$ profile. 


\section{B.1.2 Ex-post Status Gaps in the Flexible Policy Model}

The ex-post status of the Periphery $\left(S_{P}\right)$ and the Core $\left(S_{C}\right)$ are endogenously determined in SPNE. This section details the ex-post status gap for any given identity profile. This will be used for deriving the results in Section B.2.

Define $\widetilde{S G}_{\left(I D_{C}, I D_{P}\right)}\left(r_{C}^{*}-r_{P}^{*}\right)$ as the flexible policy model ex-post status gap between the Core and the Periphery (i.e. $\left.S_{C}-S_{P}\right)$ in SPNE, given identity profile $\left(I D_{C}, I D_{P}\right)$ when the level of fundamental differences between the countries is $r_{C}^{*}-r_{P}^{*}$.

When the Periphery identifies nationally the policies and cutoffs in SPNE in the flexible model are identical to those in the sticky one (see Lemmas B.1 and B.3). Thus, $\widetilde{S G}_{(C, P)}\left(r_{C}^{*}-\right.$ $\left.r_{P}^{*}\right)$ is given by equation (13) and $\widetilde{S G}_{(E, P)}\left(r_{C}^{*}-r_{P}^{*}\right)$ is given by equation (15). However, when the Periphery identifies with Europe the policies and cutoffs in SPNE in the flexible model are different, and as a result so are the ex-post status gaps. These are directly derived from equation (3) and Lemmas B.2 and B.4:

$$
\begin{gathered}
\widetilde{S G}_{(C, E)}\left(r_{C}^{*}-r_{P}^{*}\right)=\left\{\begin{array}{ccc}
\sigma_{C}-\sigma_{P}+\left(r_{C}^{*}-r_{P}^{*}\right)^{2} & \text { if } & r_{C}^{*}-r_{P}^{*} \leq \widetilde{R_{1}}(C, E) \\
\sigma_{C}-\sigma_{P}-\frac{1}{1+\gamma}(1+\gamma-2 \gamma \lambda)\left(r_{C}^{*}-r_{P}^{*}\right)^{2}+ & \text { if } & \widetilde{R_{1}}(C, E)<r_{C}^{*}-r_{P}^{*} \leq \widetilde{R_{2}}(C, E) \\
\frac{1}{1+\gamma} 2\left(r_{C}^{*}-r_{P}^{*}\right) \sqrt{(1+\gamma)^{2} \triangle-\gamma \lambda(1+\gamma-\gamma \lambda)\left(r_{C}^{*}-r_{P}^{*}\right)^{2}} & \text { if } & r_{C}^{*}-r_{P}^{*}>\widetilde{R_{2}}(C, E) \\
\sigma_{C}-\sigma_{P} & & (19)
\end{array}\right. \\
\widetilde{S G}_{(E, E)}\left(r_{C}^{*}-r_{P}^{*}\right)=\left\{\begin{array}{ccc}
\sigma_{C}-\sigma_{P}+\frac{1-\gamma+2 \gamma \lambda}{1+\gamma}\left(r_{C}^{*}-r_{P}^{*}\right)^{2} & \text { if } & r_{C}^{*}-r_{P}^{*} \leq \widetilde{R_{1}}(E, E) \\
\sigma_{C}-\sigma_{P}-\frac{1}{1+\gamma}(1+\gamma-2 \gamma \lambda)\left(r_{C}^{*}-r_{P}^{*}\right)^{2}+ & \text { if } & \widetilde{R}_{1}(E, E)<r_{C}^{*}-r_{P}^{*} \leq \widetilde{R_{2}}(E, E) \\
\frac{1}{1+\gamma} 2\left(r_{C}^{*}-r_{P}^{*}\right) \sqrt{(1+\gamma)^{2} \triangle-\gamma \lambda(1+\gamma-\gamma \lambda)\left(r_{C}^{*}-r_{P}^{*}\right)^{2}} & & \\
\sigma_{C}-\sigma_{P} & \text { if } & r_{C}^{*}-r_{P}^{*}>\widetilde{R_{2}}(E, E) \\
& & (20)
\end{array}\right.
\end{gathered}
$$

\section{B.2 Social Identity Equilibrium (SIE) in the Flexible Policy Model}

We now allow social identities to be endogenous. Since the problem of choosing social identity (Section 4) is unaffected by the Core's ability to adjust its policy in case of breakup, we directly proceed to the analysis of Social Identity Equilibrium. Our main equilibrium results continue to hold in the flexible policy model. Propositions B.4, B.5 and B.6 state these results. Proofs are obtained by tracing the same steps introduced in the proofs for the equivalent Propositions 5, 6 and 7 from the benchmark sticky model. 
Proposition B.4. When there are no ex-ante differences in status, i.e. $\sigma_{C}=\sigma_{P}=\sigma_{E}$ then:

a. An SIE exists.

b. In almost any SIE in which the union is sustained, the social identity profile is $(C, E)$. The only exceptions are when $r_{C}^{*}=r_{P}^{*}$ and when $r_{C}^{*}-r_{P}^{*}=\widetilde{R_{2}}(C, P)$; in these cases other identity profiles can also be sustained under unification.

c. When fundamental differences are smaller than $\widetilde{R_{2}}(C, P)$, SIE implies unification. When fundamental differences are larger than $\widetilde{R_{2}}(C, E)$, SIE implies breakup. For fundamental differences between $\widetilde{R_{2}}(C, P)$ and $\widetilde{R_{2}}(C, E)$, both unification and breakup can occur in SIE.

d. The profile $(E, E)$ can be sustained either when fundamental differences are zero or under breakup and large fundamental differences.

Proposition B.5. When the Core has ex-ante higher status, and the Periphery has ex-ante lower status than Europe, i.e. $\sigma_{C}>\sigma_{E}>\sigma_{P}$, then there exists a unique SIE. Furthermore the social identity profile is $(C, E)$, and the union is sustained if and only if fundamental differences are smaller than $\widetilde{R_{2}}(C, E)$.

Proposition B.6. When the Core has ex-ante higher status, and the Periphery has ex-ante lower status than Europe, i.e. $\sigma_{P}>\sigma_{E}>\sigma_{C}$, then:

a. An SIE exists.

b. Breakup can occur when fundamental differences are smaller than $\widetilde{R_{2}}(C, E)$.

c. In any SIE in which breakup occurs, the social identity profile is $(E, P)$.

d. There exists an intermediate range of fundamental differences in which both unification and breakup can occur. However, in any SIE in this range in which unification occurs, the Periphery identifies with the union.

e. The profile $(E, E)$ can be sustained only when fundamental differences between the countries are at some intermediate range. 